Article

\title{
An Analysis of Voltage Quality in a Nanogrid during Islanded Operation
}

\author{
Jakob Nömm *, Sarah K. Rönnberg * and Math H. J. Bollen * \\ Electric Power Engineering, Luleå University of Technology, 93187 Skellefteå, Sweden \\ * Correspondence: jakob.nomm@ltu.se (J.N.); sarah.ronnberg@ltu.se (S.K.R.); math.bollen@ltu.se (M.H.J.B.)
}

Received: 21 January 2019; Accepted: 13 February 2019; Published: 15 February 2019

\begin{abstract}
Voltage quality data has been collected in a single house nanogrid during 48 weeks of islanded operation and 54 weeks of grid-connected operation. The voltage quality data contains the voltage total harmonic distortion (THD), odd harmonics 3 to 11 and 15, even harmonics 4 to 8 , voltage unbalance, short-term flicker severity (Pst) and long-term flicker severity (Plt) values, and voltage variations at timescales below $10 \mathrm{~min}$. A comparison between islanded and grid-connected operation values was made, were some of the parameters were compared to relevant grid standard limits. It is shown that some parameters exceed the defined limits in the grid-standards during islanded operation. It was also found that the islanded operation has two modes of operation, one in which higher values of the short circuit impedance, individual harmonic impedance, harmonic voltage distortion and voltage unbalance were reached.
\end{abstract}

Keywords: harmonics; islanded operation; nanogrids; power quality; voltage unbalance

\section{Introduction}

Microgrids and nanogrids can provide economical gains in the form of price reductions for consumers and increased revenue for grid owners [1]. They could also provide an improved technical solutions such as energy loss reduction and better reliability than a regular utility connection for certain geographical areas [1,2]. The international council on large electric systems (CIGRE) WG C6.22 defines microgrids as: "electricity distribution systems containing loads and distributed energy resources, (such as distributed generators, storage devices, or controllable loads) that can be operated in a controlled, coordinated way either while connected to the main power network or while islanded" [3]. The term nanogrid was suggested in [4] for defining a small microgrid, which could be a single residential house.

There is a lack of published papers that contain voltage quality measurements that span several months or years for nanogrids in islanded operation. These measurements are needed to establish the differences in performance between islanded operation and grid-connected operation. The measurements would also make it possible to evaluate if problems can appear for connected equipment during islanded operation.

In this paper, long term measurements of voltage quality are presented that have been collected in a single house nanogrid during 48 weeks of islanded operation and 54 weeks of grid-connected operation. Some of the measured voltage quality parameters have been compared with the limits defined in standards EN 50160 [5] and IEEE 519-2014 [6]. The specified standards do not include voltage quality limits for islanded operation, so the limits in the standards are only used as a reference for islanded operation.

The main contribution of this paper is the analysis and presentation of long-term voltage quality measurements collected in a nanogrid during islanded operation. All the used equipment in the 
nanogrid is commercially available and therefore similar performance is expected for other nanogrids like the one presented in this paper.

\section{The Nanogrid}

The single house nanogrid that is studied in this paper is located in the southern part of Sweden and has a $22.6 \mathrm{kWp}$ solar installation, $144 \mathrm{kWh}$ lead acid battery storage, $1100 \mathrm{kWh}$ hydrogen storage and a $15 \mathrm{kVA}$ diesel backup generator. The nanogrid is designed to operate as a $50 \mathrm{~Hz}$ three-phase system where each phase has a phase-to-neutral voltage of $230 \mathrm{~V}$ root mean square (RMS). The consumption in the nanogrid consists of ordinary household appliances, two electric cars, a three-phase heat pump and an electrolyzer for the production of hydrogen. A simplified schematic of the nanogrid energy system can be seen in Figure 1.

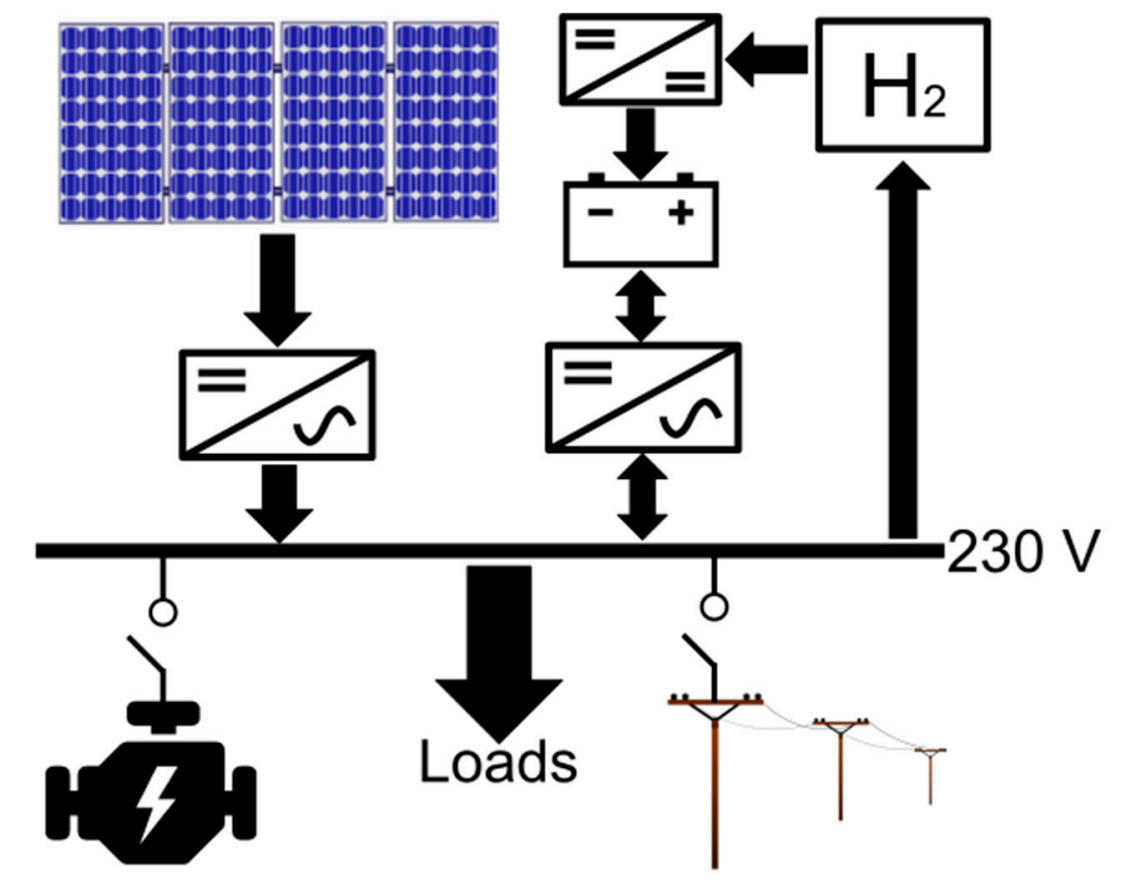

Figure 1. Simplified schematic of the energy system for the nanogrid. Reproduced with permission from [7], Nömm, J.; Rönnberg, S.K.; Bollen, M.H.J. An Analysis of Frequency Variations and its Implications on Connected Equipment for a Nanogrid during Islanded Operation. Energies 2018, $11,2456$.

The nanogrid is designed to run primarily on the produced solar power and the stored energy in the batteries and hydrogen tanks. During the day, the solar panels will supply the energy to the loads where the excess solar power will charge the batteries and power a $5 \mathrm{~kW}$ electrolyzer to convert electricity to hydrogen that is stored in high-pressure tanks. During the night, the batteries are the main supply of energy to the nanogrid; if the battery charge drops below $30 \%$, a $5 \mathrm{~kW}$ fuel cell will convert hydrogen to electricity to charge the battery. If there is a malfunction in the primary energy system, the nanogrid will connect to the low-voltage utility grid. The nanogrid also connects to the utility grid if the stored energy in the batteries and hydrogen tanks is depleted. The backup diesel generator in the nanogrid is designed to start only if both the low voltage utility grid and the primary energy system in the nanogrid fail to operate. The backup diesel generator operated for $43 \mathrm{~h}$ during the 48 week islanded operation measurement period.

The nanogrid switched to grid-connected operation mainly due to lack of energy stored in the batteries and hydrogen tanks. To avoid this, additional hydrogen storage is under construction. For more information regarding the nanogrid see [7] and [8]. 


\section{Methodology}

The measurements have been collected by an Elspec G4430 (Elspec, Caesarea, Israel) connected at the load-output of the SMA Multicluster Box (SMA, Niestetal, Germany). The SMA Multicluster Box is used in the nanogrid since there are three independent solar installations, two on the roof, each with a capacity of $10 \mathrm{~kW}$ and one on the facade with $2.6 \mathrm{~kW}$ power rating.

The parameters measured for the comparison to the limits described in EN 50160 and IEEE 519-2014 are the voltage Total Harmonic Distortion (THD), Individual odd harmonics 3rd to 11th and 15th, even harmonics 4th to 8th, Pst, Plt, and voltage unbalance. Two parameters that were also measured with no relation to any standard were the very short variations (VSV) of the voltage and RMS value of the neutral current. For the measured parameters, the total time in islanded operation was 48 weeks and 54 weeks in grid-connected operation. The 48 and 54 week measurements are assembled from shorter time windows in which the nanogrid was in islanded or grid-connected operation.

For the voltage THD measurements, there was a measurement period of 29 weeks of the total 48 weeks where the nanogrid operated continuously in islanded operation. These measurements were used to see the daily voltage THD variations.

For the analysis of the individual harmonics, the odd harmonics 3rd to 11th and 15th and even harmonics 4th to 8th were chosen since they all surpass the limits defined in either standard EN 50160 or IEEE 519-2014 sometime during the 48 week islanded operation measurements.

Another measurement period of about 8 weeks in islanded operation and about 5 weeks in grid-connected operation was used to study the variations with time in the short circuit impedance measured as the voltage drop against a current rise of larger than $4 \mathrm{~A}$ within two cycles.

\section{Results}

\subsection{Total harmonic Distortion}

The cumulative distribution function (CDF) for the 10 min values of the voltage THD during 48 weeks in islanded operation and 54 weeks in grid-connected operation can be seen in the upper part of Figure 2.

In the lower part of Figure 2, the corresponding CDF for the $3 \mathrm{~s}$ values is plotted. As expected, the $3 \mathrm{~s}$ voltage THD values reach higher values than the $10 \mathrm{~min}$ values during both islanded and grid-connected operation. It can also be observed in Figure 2 that the voltage THD is always higher during islanded operation than during grid-connected operation. The maximum values and total average values are also higher for islanded operation which can be seen in Table 1.

Table 1. $95 \%$ Confidence interval (CI) for the $10 \mathrm{~min}$ values, the maximum 10 min value and total average value for all three phases in islanded and grid-connected operation.

\begin{tabular}{cccccc}
\hline $\begin{array}{c}\text { Operational } \\
\text { State }\end{array}$ & $\begin{array}{c}\mathbf{9 5 \%} \text { CI } 10 \mathrm{~min} \\
\text { Value }\end{array}$ & $\begin{array}{c}\text { Max } 10 \mathrm{~min} \\
\text { Value }\end{array}$ & $\begin{array}{c}\mathbf{9 5 \%} \text { CI 3 s } \\
\text { Value }\end{array}$ & $\begin{array}{c}\text { Max 3 s } \\
\text { Value }\end{array}$ & $\begin{array}{c}\text { Total Average } \\
\text { Value }\end{array}$ \\
\hline Islanded & 1.34 to $8 \%$ & 7.83 to $13.01 \%$ & 1.28 to $8.06 \%$ & 18.3 to $21.9 \%$ & 2.23 to $3.82 \%$ \\
Grid-connected & 0.77 to $1.88 \%$ & 2.41 to $2.47 \%$ & 0.76 to $1.88 \%$ & $\approx 2.5 \%$ & 1.08 to $1.44 \%$ \\
\hline
\end{tabular}

In Figure 3, the average voltage THD variations for each hour of the day for 29 weeks can be seen for all three phases. During 29 out of 48 weeks the nanogrid operated in islanded operation that lasted continually throughout the day without connections to the utility grid. 

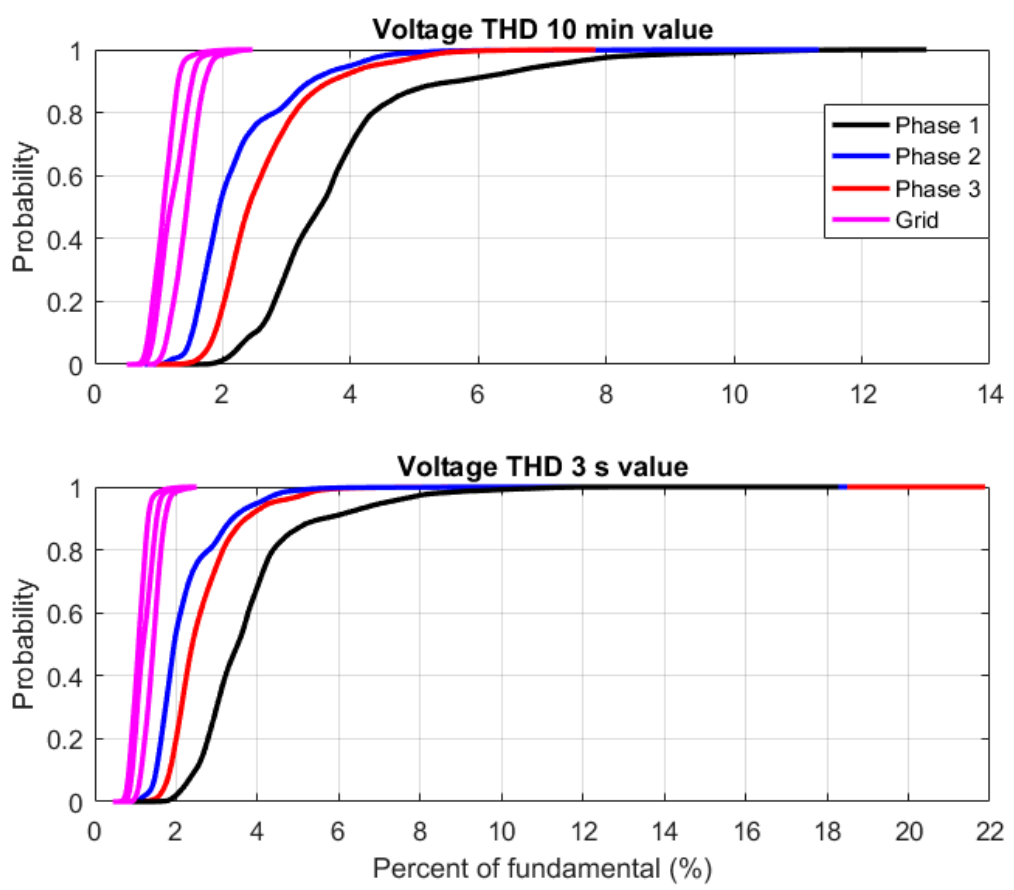

Figure 2. Cumulative distribution function (CDF) for the 10 min voltage Total Harmonic Distortion (THD) for the nanogrid during islanded and grid-connected operation (top) and the CDF for the $3 \mathrm{~s}$ voltage THD during grid-connected and islanded operation (bottom). Note that the horizontal axis is different for each plot.
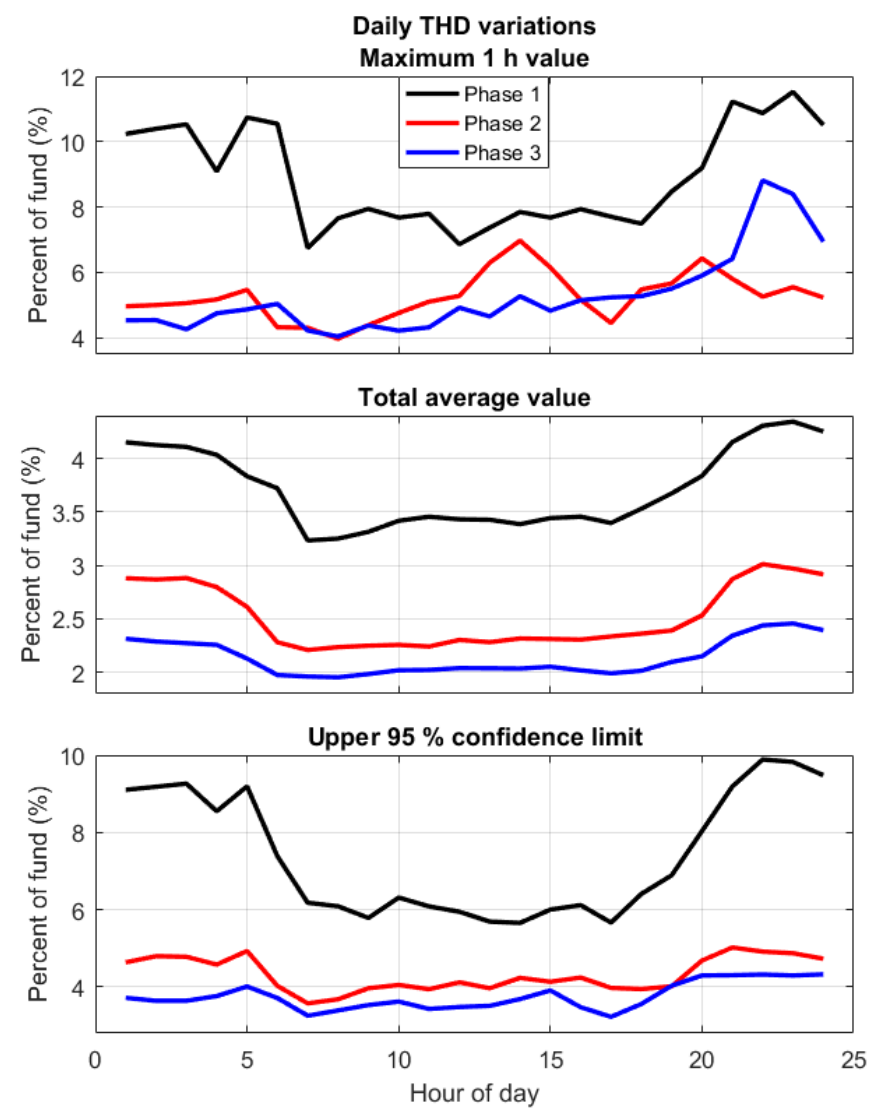

Figure 3. The $1 \mathrm{~h}$ maximum THD value, total average THD value and upper $95 \%$ confidence limit for every hour during the day for 29 weeks of continuous islanded operation. The black, red and blue color represents the three phases. Note the difference in vertical scale for each plot. 
It can be seen that the maximum $1 \mathrm{~h}$ values are reached during the night for phase 1 and 3. For phase 2, the maximum occurs in the middle of the day. The total average value and $95 \%$ confidence limit for each hour during the day reach the highest values in the morning and night for all 3 phases. Phase 3 has however a smaller variation between night and day in the total average value and 95\% confidence limit as phase 1 and 2. A more detailed view of the voltage THD variations during one day can be seen in [9].

The trend in Figure 3 shows larger THD values during the night than during the day. This indicates that when the solar production starts, the voltage THD level drops due to more parallel sources being activated and increases when there are fewer parallel sources available. One example when the voltage THD suddenly increases during the evening at about the time when the sun sets can be seen in Figure 4 . It can be seen that even though the active power remains almost constant the voltage THD increases for all three phases which also can be seen in the voltage waveform. The current THD also increases for phase 1 and 3 and decreases for phase 2 which can also be seen in the current waveform. The reactive power changes somewhat for the three phases and the frequency throughout Figure 4 was around $49 \mathrm{~Hz}$.
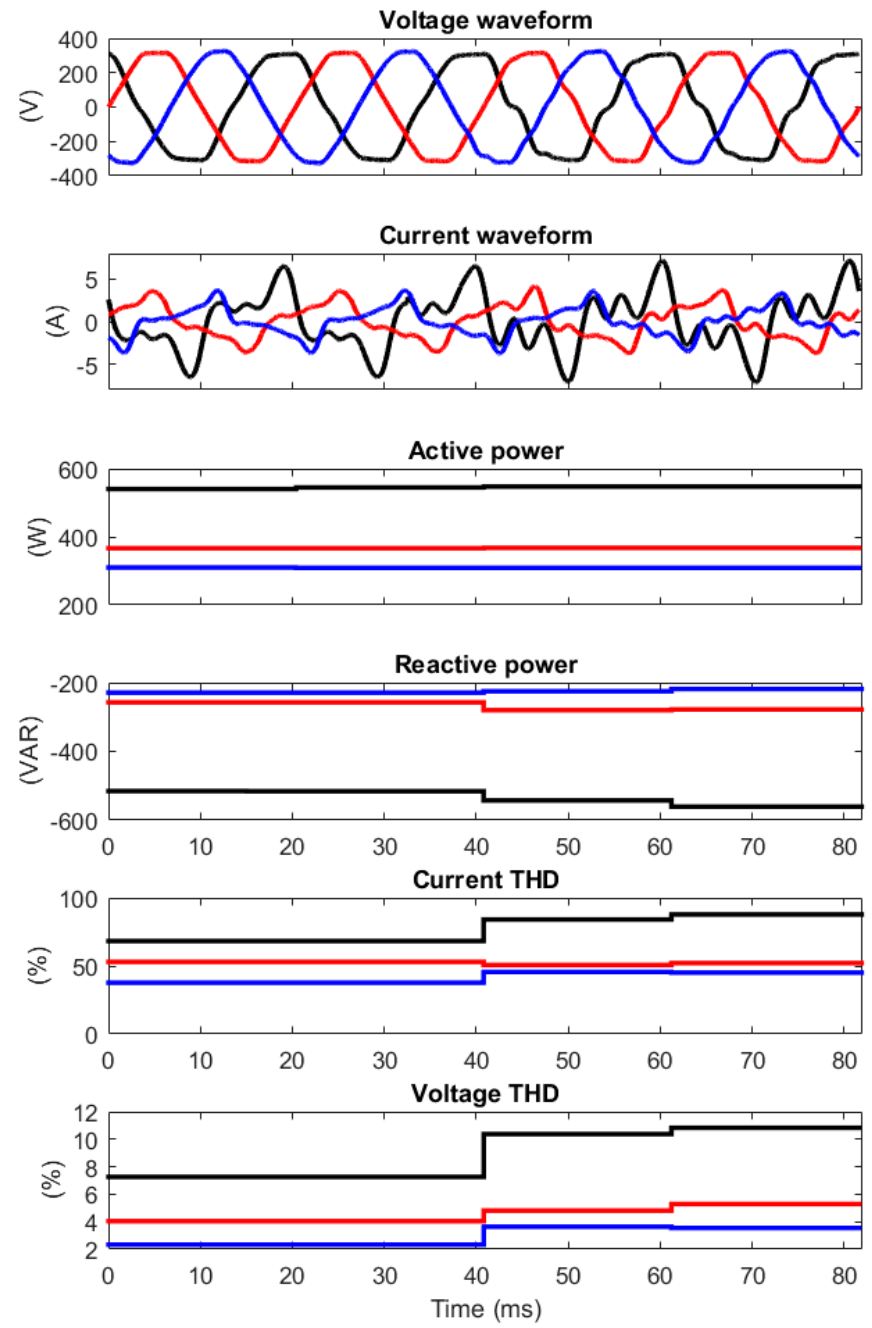

Figure 4. Example of an occasion when the voltage THD increases in the evening. The voltage waveform is at the top followed by the current waveform, active power, reactive power, current THD and voltage THD. The black, red and blue color represents the three phases. 


\subsection{Individual Harmonics}

In Figure 5, the odd voltage and current harmonics 3 to 9 are presented for the 1-cycle period ending at about $20 \mathrm{~ms}$ and $80 \mathrm{~ms}$ in Figure 4. The 3rd voltage harmonic is about the same for phase 1 and 2 and slightly lower for phase 3. After the transition from 8 to 12\% voltage THD (seen at around $40 \mathrm{~ms}$ in Figure 4), the 5th voltage harmonic increases for two of the three phases and the 7th and 9 th voltage harmonic also increase for all three phases. All of the current harmonics increase for phase 1 but the 3rd harmonic for phase 2 decreases by $1.4 \%$ and the 3rd and 7th harmonic for phase 3 decrease by 4.35 and $1.34 \%$ respectively.

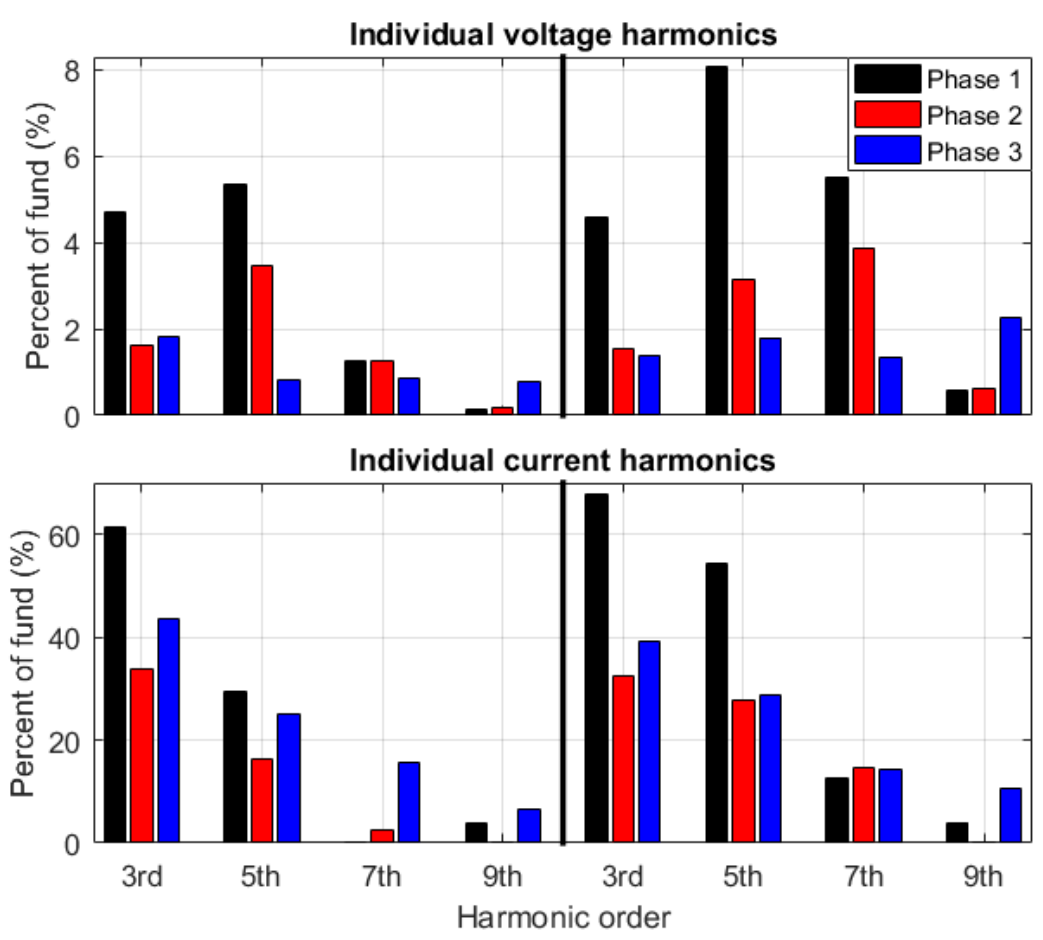

Figure 5. Individual harmonics of the voltage THD in Figure 4 where the left side is the individual harmonics at the end of the 1-cycle period at about $20 \mathrm{~ms}$ and the right side at about $80 \mathrm{~ms}$.

The $95 \%$ confidence limit for the 10 min values for the odd voltage harmonics 3rd to 11 th and 15th and even voltage harmonics 4 th to 8 th can be seen in the upper part of Figure 6.

The maximum 10 min value can be seen in the lower part of Figure 6. It can be seen that both the maximum $10 \mathrm{~min}$ value and the $95 \%$ confidence limit value are higher during islanded operation. The odd harmonics differ the most in magnitude from the grid-connected measurements, except the $95 \%$ confidence limit value for the 15 th harmonic. Phase 1 has higher $95 \%$ confidence limits for the odd harmonics until the 11th. In the maximum 10 min values, the even harmonics are several times higher in islanded operation compared to grid-connected operation. The $95 \%$ confidence limit for the even harmonics is close to zero for the grid-connected operation.

At a shorter time scale of $3 \mathrm{~s}$, which can be seen in Figure 7, the 95\% confidence limit is about the same as the $95 \% 10$ min values in Figure 6. But the maximum $3 \mathrm{~s}$ value is larger than the $10 \mathrm{~min}$ maximum value. The even harmonics have the highest increase from 10 min maximum values to $3 \mathrm{~s}$ maximum values. Phase 2 had the lowest 10 min maximum value for most of the harmonic orders, but for the $3 \mathrm{~s}$ values it has the highest value for most of the harmonic orders. 

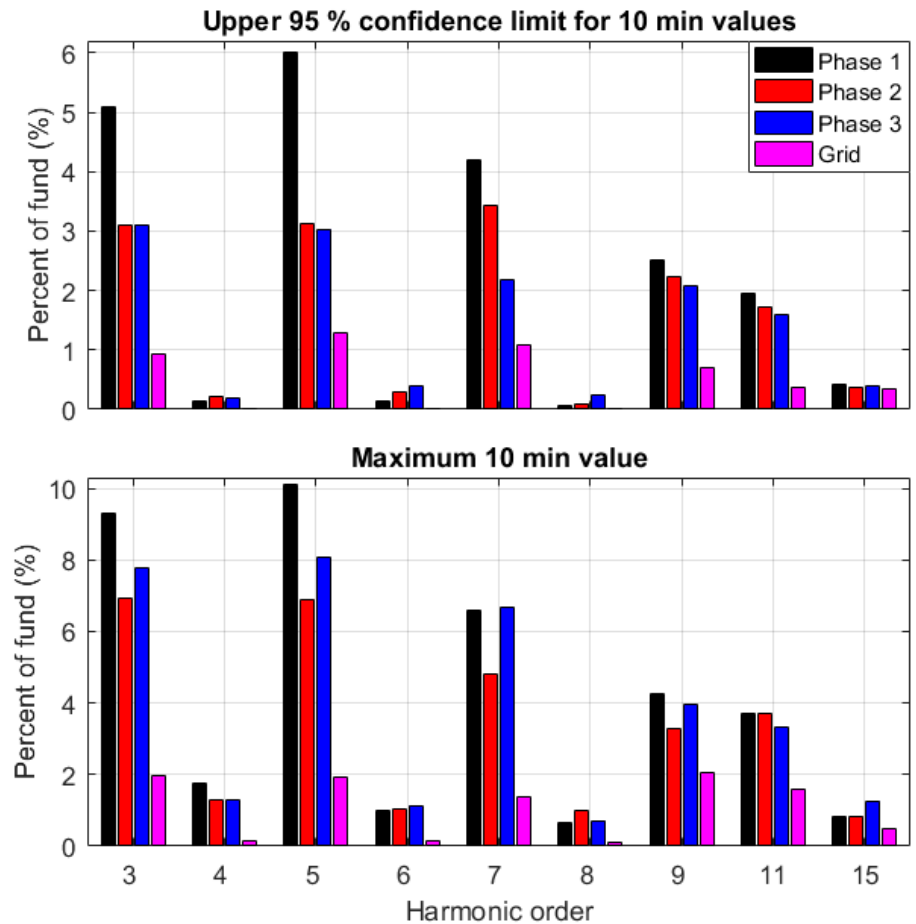

Figure 6. $10 \mathrm{~min} 95 \%$ confidence limit value (top) and the maximum $10 \mathrm{~min}$ value in the measurements (bottom) for the odd harmonics 3rd to 11th and 15th and even harmonics 4th to 8th. The black, red and blue color represents phase 1 to 3 in islanded mode. Purple color represents all three phases during grid-connected operation since the distortion differs substantially less between the phases in comparison to islanded operation.
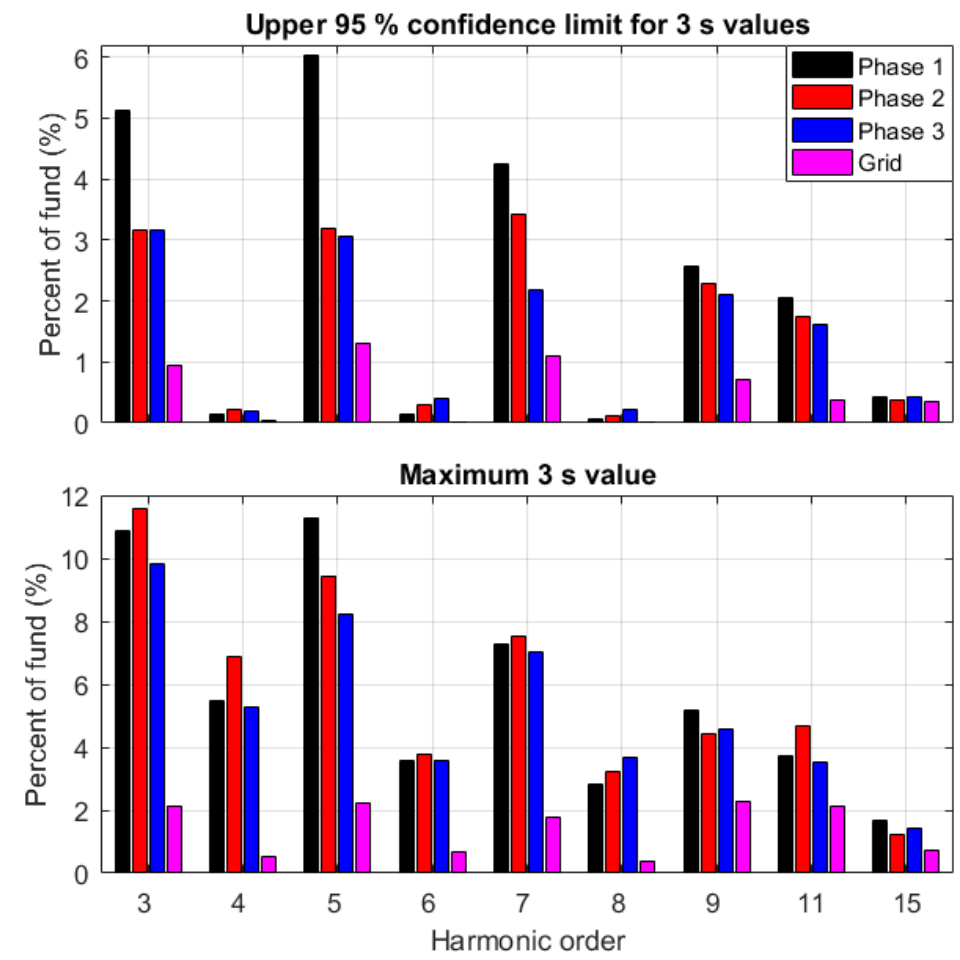

Figure 7. 3 s maximum 95\% confidence limit value (top) and the maximum $3 \mathrm{~s}$ value in the measurements (bottom) for the odd harmonics 3rd to 11th and 15th and even harmonics 4th to 8th. The black, red and blue color represents phase 1 to 3 in islanded mode. Purple color represents all three phases during grid-connected operation. 
The total average values for both grid-connected and islanded operation can be seen in Table 2.

Table 2. Total average value for each measured voltage harmonic for all three phases.

\begin{tabular}{|c|c|c|c|c|c|c|c|c|c|}
\hline $\begin{array}{c}\text { Operational } \\
\text { State }\end{array}$ & 3 rd $(\%)$ & 4th (\%) & 5th (\%) & 6th (\%) & 7th $(\%)$ & 8th (\%) & 9th (\%) & 11th (\%) & 15th (\%) \\
\hline Islanded & $\begin{array}{c}0.95 \text { to } \\
1.96\end{array}$ & $\begin{array}{c}0.01 \text { to } \\
0.02\end{array}$ & $\begin{array}{c}0.83 \text { to } \\
2.0\end{array}$ & $\begin{array}{c}0.016 \text { to } \\
0.04\end{array}$ & $\begin{array}{c}0.61 \text { to } \\
1.45\end{array}$ & $\begin{array}{c}0.008 \text { to } \\
0.016\end{array}$ & $\begin{array}{c}1.20 \text { to } \\
1.38\end{array}$ & $\begin{array}{c}0.63 \text { to } \\
0.66\end{array}$ & $\begin{array}{c}0.20 \text { to } \\
0.18\end{array}$ \\
\hline Grid-connected & $\begin{array}{c}0.30 \text { to } \\
0.52\end{array}$ & $\approx 0.001$ & $\begin{array}{c}0.66 \text { to } \\
0.90\end{array}$ & $\approx 10^{-4}$ & $\begin{array}{c}0.55 \text { to } \\
0.60\end{array}$ & $\approx 10^{-5}$ & $\begin{array}{c}0.34 \text { to } \\
0.44\end{array}$ & $\begin{array}{c}0.14 \text { to } \\
0.17\end{array}$ & $\begin{array}{c}0.10 \text { to } \\
0.15\end{array}$ \\
\hline
\end{tabular}

\subsection{Voltage Unbalance}

The 10 min voltage unbalance for both islanded operation and grid-connected operation can be seen in Figure 8. The voltage unbalance is for the majority of the measured time lower in islanded operation than in grid-connected operation. The maximum $10 \mathrm{~min}$ voltage unbalance was $4.6 \%$ for islanded operation and 1.77 for grid-connected operation. In Figures 14-16 the occurrence of the maximum voltage unbalance value can be seen. A summary of the $95 \% \mathrm{CI}$, maximum $10 \mathrm{~min}$ value and total average value in islanded and grid-connected operation can be seen in Table 3.

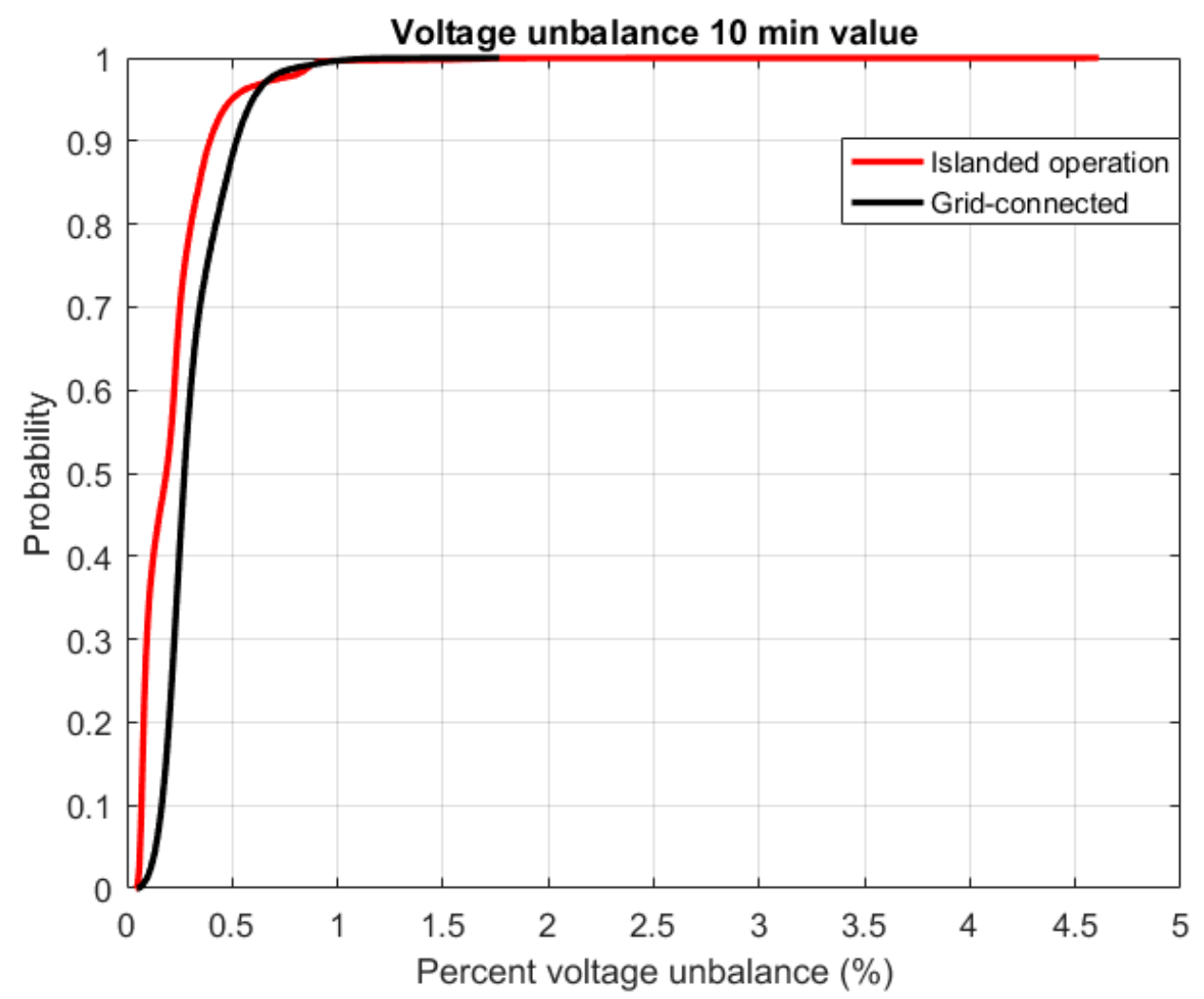

Figure 8. $\mathrm{CDF}$ for the $10 \mathrm{~min}$ voltage unbalance values in the nanogrid during islanded and grid-connected operation.

Table 3. $95 \%$ confidence interval, the maximum $10 \mathrm{~min}$ value and total average value for all three phases in islanded and grid-connected operation.

\begin{tabular}{cccc}
\hline Operational State & $\mathbf{9 5 \%}$ CI 10 min Value & Max 10 min Value & Total Average Value \\
\hline Islanded & 0.06 to $0.72 \%$ & $4.6 \%$ & $0.22 \%$ \\
Grid-connected & 0.11 to $0.68 \%$ & $1.77 \%$ & $0.31 \%$ \\
\hline
\end{tabular}




\subsection{Voltage Fluctuations}

The CDF of the Pst values for grid-connected and islanded operation can be seen in Figure 9. The islanded operation data reaches lower Pst values than in grid-connected operation for 95\% and $33 \%$ of the total measured time for phase 2 and 1. Phase 3 has larger Pst values for the majority of the time when comparing to the grid-connected operation Pst values. All three phases have higher maximum values than the grid-connected measurements. A summary of the $95 \% \mathrm{CI}$, maximum value and total average value for all three phases in islanded and grid-connected operation can be seen in Table 4.
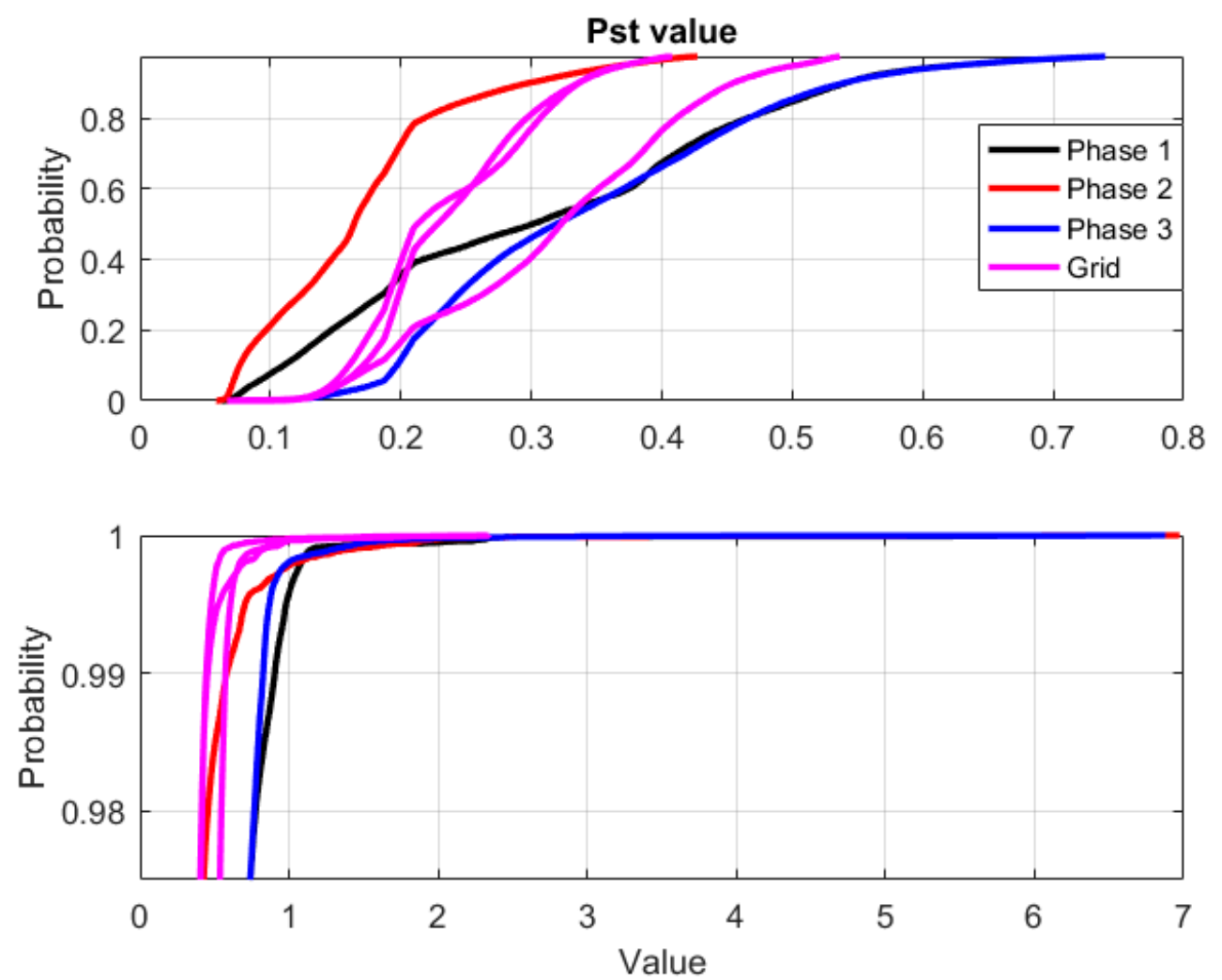

Figure 9. CDF for the Pst values for grid-connected and islanded operation where the interval 0 to $97.5 \%$ is displayed at the top and the remaining upper $2.5 \%$ is displayed in the bottom. The black, red and blue color represents phase 1 to 3 in islanded mode. Purple color represents all three phases during grid-connected operation.

Table 4. 95\% confidence interval, the maximum $10 \mathrm{~min}$ value and total average value for all three phases in islanded and grid-connected operation.

\begin{tabular}{cccc}
\hline Operational State & $\mathbf{9 5 \%}$ CI & Max Value & Total Average Value \\
\hline Islanded & 0.06 to 0.74 & 6.43 to 7 & 0.18 to 0.35 \\
Grid-connected & 0.14 to 0.52 & 2.3 to 2.34 & 0.24 to 0.32 \\
\hline
\end{tabular}

The CDF of the Plt values for islanded and grid-connected operation can be seen in Figure 10. It can be seen that phase 1 and 2 have lower Plt values for $91 \%$ and $35 \%$ of the total measured time in islanded operation when compared to grid-connected operation. Phase 3 has lower Plt values for about $45 \%$ of the total measured time than the phase with highest Plt values in grid-connected operation. All three phases reach higher maximum Plt values in islanded operation. The 95\% CI, maximum value and total average value can be seen in Table 5 . 

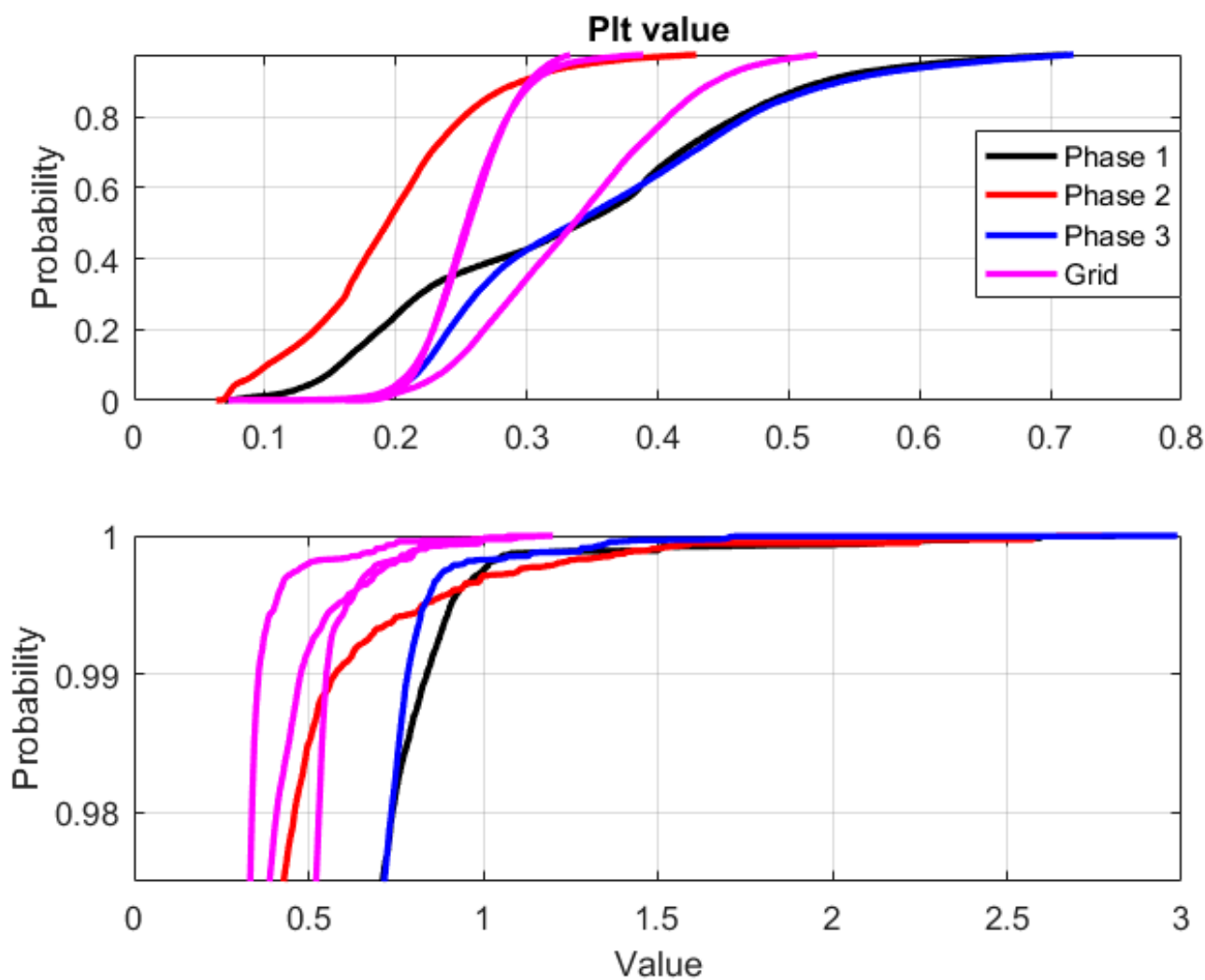

Figure 10. CDF for the Plt values in grid-connected and islanded operation where the interval 0 to $97.5 \%$ is displayed at the top and the remaining upper $2.5 \%$ is displayed in the bottom. The black, red and blue color represents phase 1 to 3 in islanded mode. Purple color represents all three phases during grid-connected operation.

Table 5. 95\% confidence interval, the maximum 10 min value and total average value for all three phases in islanded and grid-connected operation.

\begin{tabular}{cccc}
\hline Operational State & $\mathbf{9 5 \%} \mathbf{C I}$ & Maximum Value & Total Average Value \\
\hline Islanded & 0.07 to 0.72 & 2.78 to 2.99 & 0.21 to 0.36 \\
Grid-connected & 0.19 to 0.52 & 1.16 to 1.2 & $0.26 \% 0.34$ \\
\hline
\end{tabular}

Voltage Variations below 10 Min Values

The variations in the voltage that are on a shorter time scale than $10 \mathrm{~min}$ are calculated using the very short variations (VSV) of the voltage. It was introduced by $[10,11]$ to quantify the difference between very-short time scale (one to several seconds) voltage RMS values and the short time scale (10 min) voltage RMS value. The $10 \mathrm{~min}$ and $3 \mathrm{~s} \mathrm{VSV} \mathrm{values} \mathrm{for} \mathrm{grid-connected} \mathrm{and} \mathrm{islanded} \mathrm{operation}$ can be seen in Figure 11 where both the 10 min and $3 \mathrm{~s}$ VSV values are lower for the majority of the time for islanded operation. The $3 \mathrm{~s} \mathrm{VSV}$ values reach higher maximum values in islanded operation. A summary of the $95 \%$ CI, maximum values and total average value can be seen in Tables 6 and 7 .

Table 6. 95\% confidence interval, the maximum $10 \mathrm{~min}$ value and total average value for all three phases in islanded and grid-connected operation.

\begin{tabular}{cccc}
\hline Operational State & $\mathbf{9 5 \%}$ CI 10 $\mathbf{~ m i n}$ & Max 10 min Value & Total Average Value \\
\hline Islanded & 0.013 to 0.56 & 4.6 to 6.34 & 0.095 to 0.15 \\
Grid-connected & 0.18 to 1.9 & 5.75 to 7.89 & 0.61 to 0.81 \\
\hline
\end{tabular}



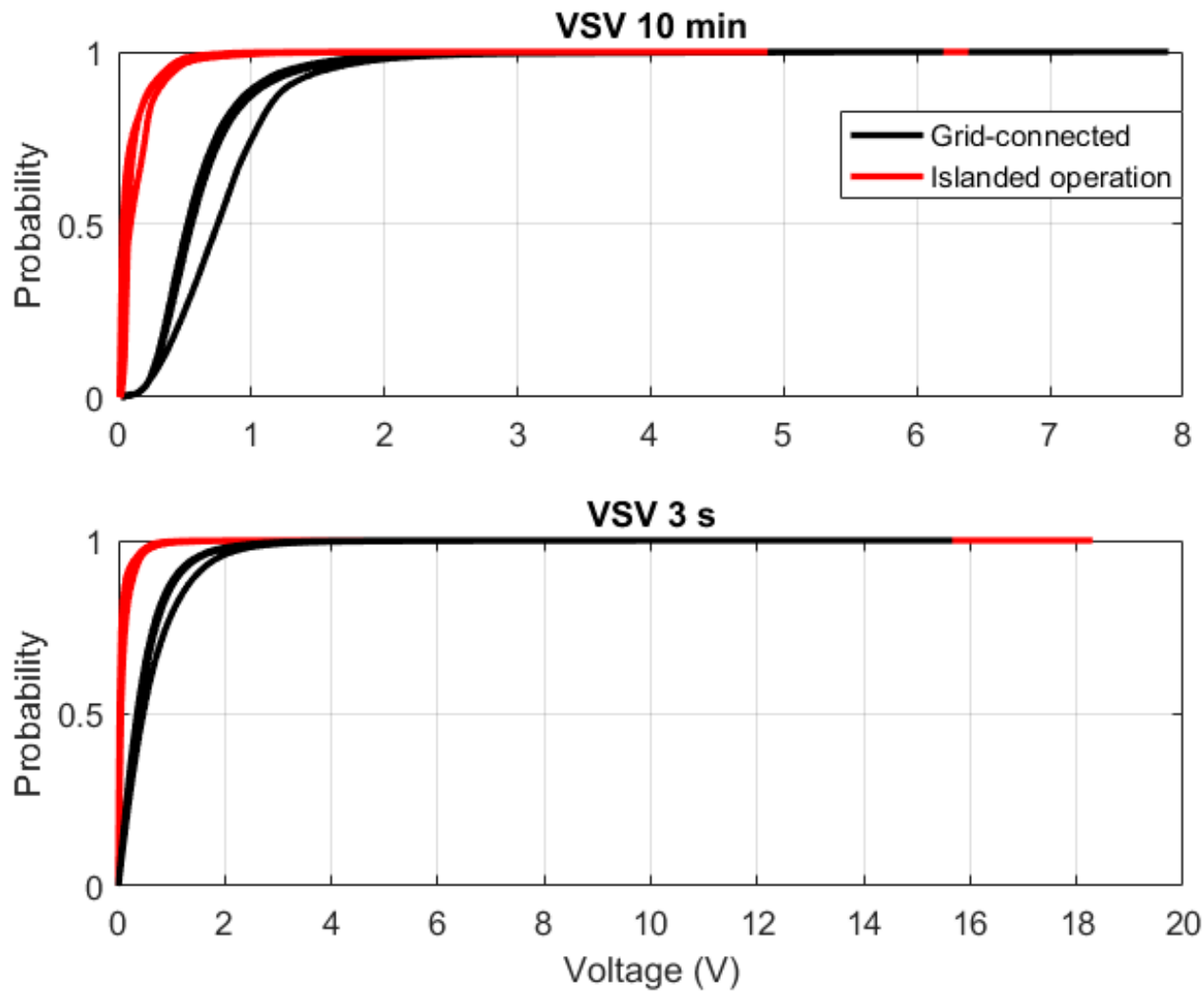

Figure 11. CDF for the 10 min very short variations (VSV) values (top) and the $3 \mathrm{~s}$ VSV values (bottom) for islanded and grid-connected operation.

Table 7. 95\% confidence interval, the maximum $3 \mathrm{~s}$ value and total average value for all three phases in islanded and grid-connected operation.

\begin{tabular}{cccc}
\hline Operational State & $\mathbf{9 5 \%}$ CI $\mathbf{3 ~ s}$ & Max 3 s Value & Total Average Value \\
\hline Islanded & $\approx 0$ to 0.58 & 15.52 to 18.3 & 0.07 to 0.11 \\
Grid-connected & 0.015 to 2.32 & 10.6 to 15.7 & 0.50 to 0.66 \\
\hline
\end{tabular}

\subsection{Neutral Current}

The CDF for the 10 min RMS neutral current for 48 weeks of islanded operation and 54 weeks of grid-connected operation can be seen in Figure 12.

The $50 \mathrm{~Hz}$ component was always several times larger than the zero sequence components where the 3rd harmonic reached a maximum value of 6 A during the 48 week measurement period in islanded operation. For both islanded and grid-connected operation, the line to neutral voltage was close to $0 \mathrm{~V}$. The neutral current reached about the same maximum values of around $42 \mathrm{~A}$ in islanded and grid-connected operation. However, during islanded operation the $10 \mathrm{~min}$ values are for the most part higher than the grid-connected values. A summary of the $95 \% \mathrm{CI}$, maximum values and total average value can be seen in Table 8 .

Table $8.95 \%$ confidence interval, the maximum $10 \mathrm{~min}$ value and total average value for all three phases in islanded and grid-connected operation.

\begin{tabular}{cccc}
\hline Operational State & $\mathbf{9 5 \%}$ CI $\mathbf{1 0}$ min & Max 10 min Value & Total Average Value \\
\hline Islanded & 2.15 to 17.6 & 41.4 & 5 \\
Grid-connected & 1.2 to 15.1 & 41.8 & 3.6 \\
\hline
\end{tabular}




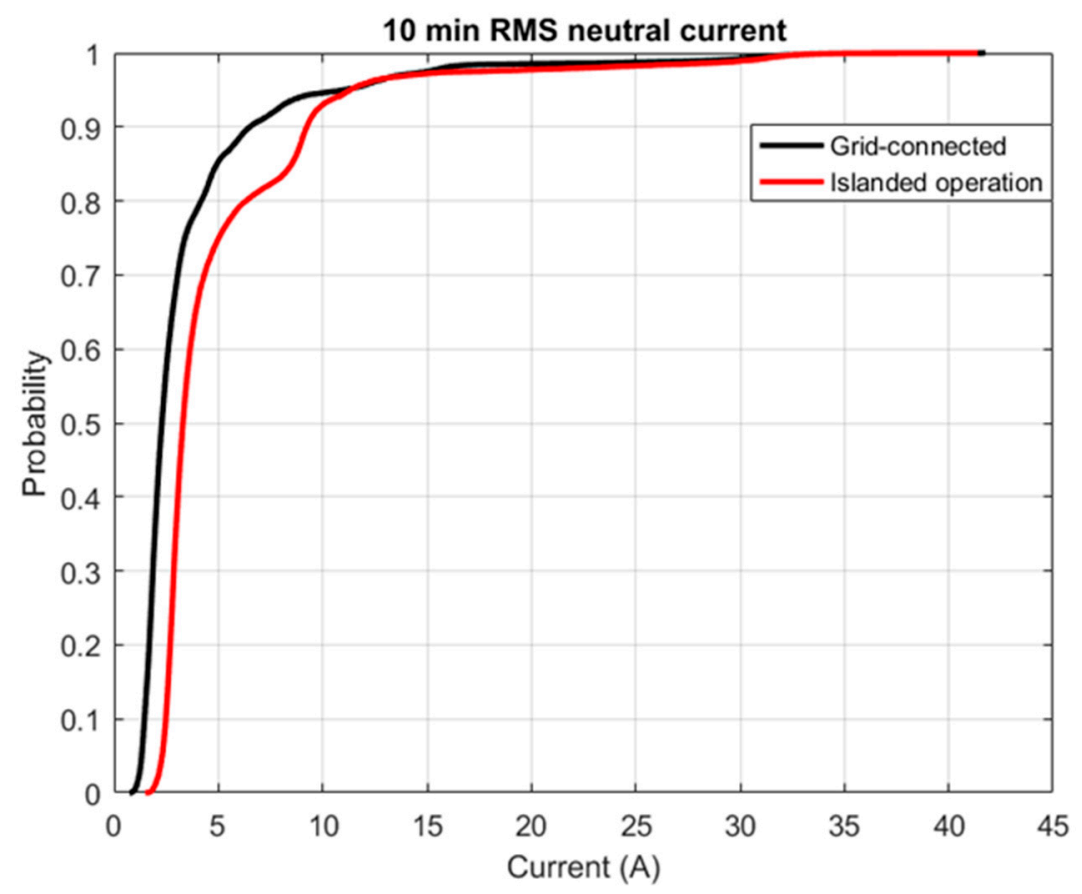

Figure 12. CDF for the $10 \mathrm{~min}$ RMS neutral current during islanded and grid-connected operation.

\subsection{Operational Modes during Islanded Operation.}

The short circuit impedance is extracted from a 13 weeks continuous period. During this 13 week period, the nanogrid operated part of the time in islanded operation and part of the time in grid-connected operation, which can be seen in Figures 13-16. The short circuit impedance was measured as the voltage drop against a current rise of larger than 4 A within two cycles. 4 A was chosen since values lower than $2 \mathrm{~A}$ could sometimes not affect the voltage, therefore a larger value of 4 A giving a $2 \mathrm{~A}$ margin was chosen. No correlation between the current rise magnitude (4 to $26 \mathrm{~A}$ in this paper) and the short circuit impedance were found and no correlation between the starting value of the current ( 0 to $36 \mathrm{~A}$ ) and the short circuit impedance was found.

In Figure 13 two different modes of islanded operation can be distinguished, one where the short circuit impedance fluctuates between 0.1 and $1 \Omega$ and one in which it fluctuates between 0.1 and $2 \Omega$ and sometimes reaching values close to $6 \Omega$ but only for phase 2 . During the grid-connected operation the values fluctuate between 0.2 and $0.4 \Omega$. The number of samples for the different phases was $31,000,730$ and 11,000 for phase 1 to 3 respectively, giving rise to differences in the horizontal axis in Figure 13. In Figures 14-16, the 10 min voltage THD, current THD, 3rd, 5th, 7th, 9th harmonic voltage and voltage unbalance are plotted for the 13 week period. The two different modes of islanded operation are again indicated. The voltage unbalance reaches the highest levels of about $4.6 \%$ during mode 2 of the islanded operation. The voltage THD, 3rd, 5th and 7th harmonic voltage is also larger in mode 2 for all three phases during the majority of the measured period. The 9 th harmonic is for the most part lower in mode 2 for all three phases. 

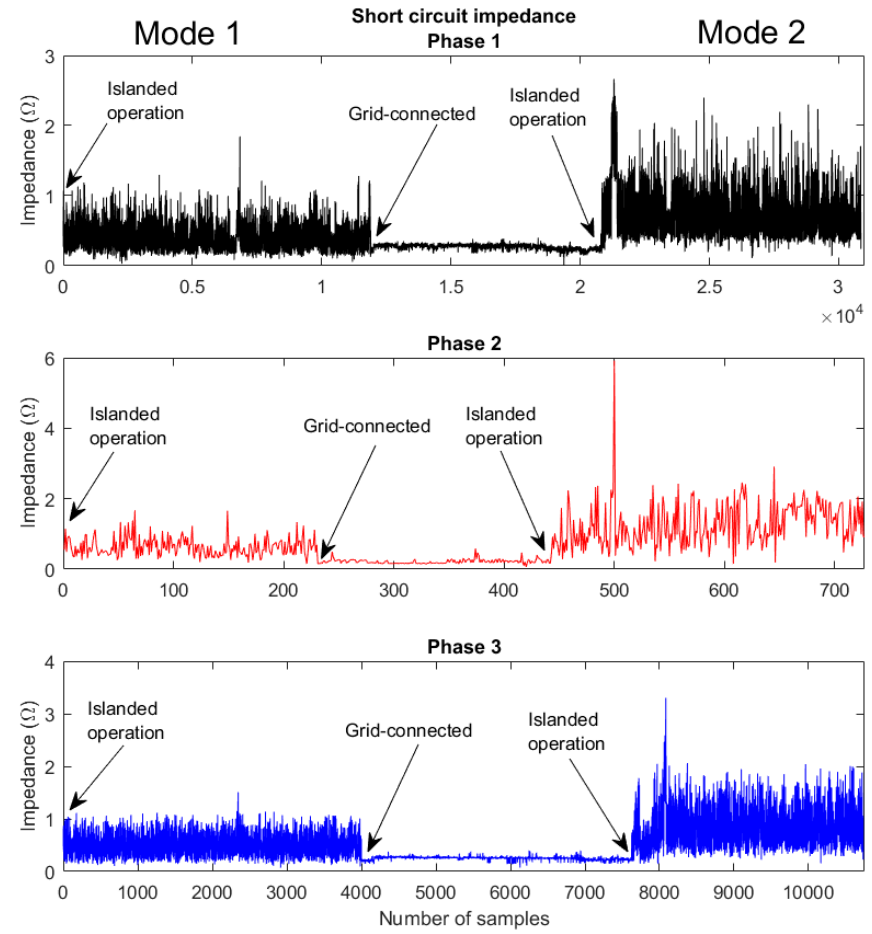

Figure 13. Short circuit impedance for 13 weeks of islanded and grid-connected measurements. The number of samples are around 31,000, 730 and 11,000 for phase 1 to 3 respectively. Note the difference in horizontal scale for each sub-plot.
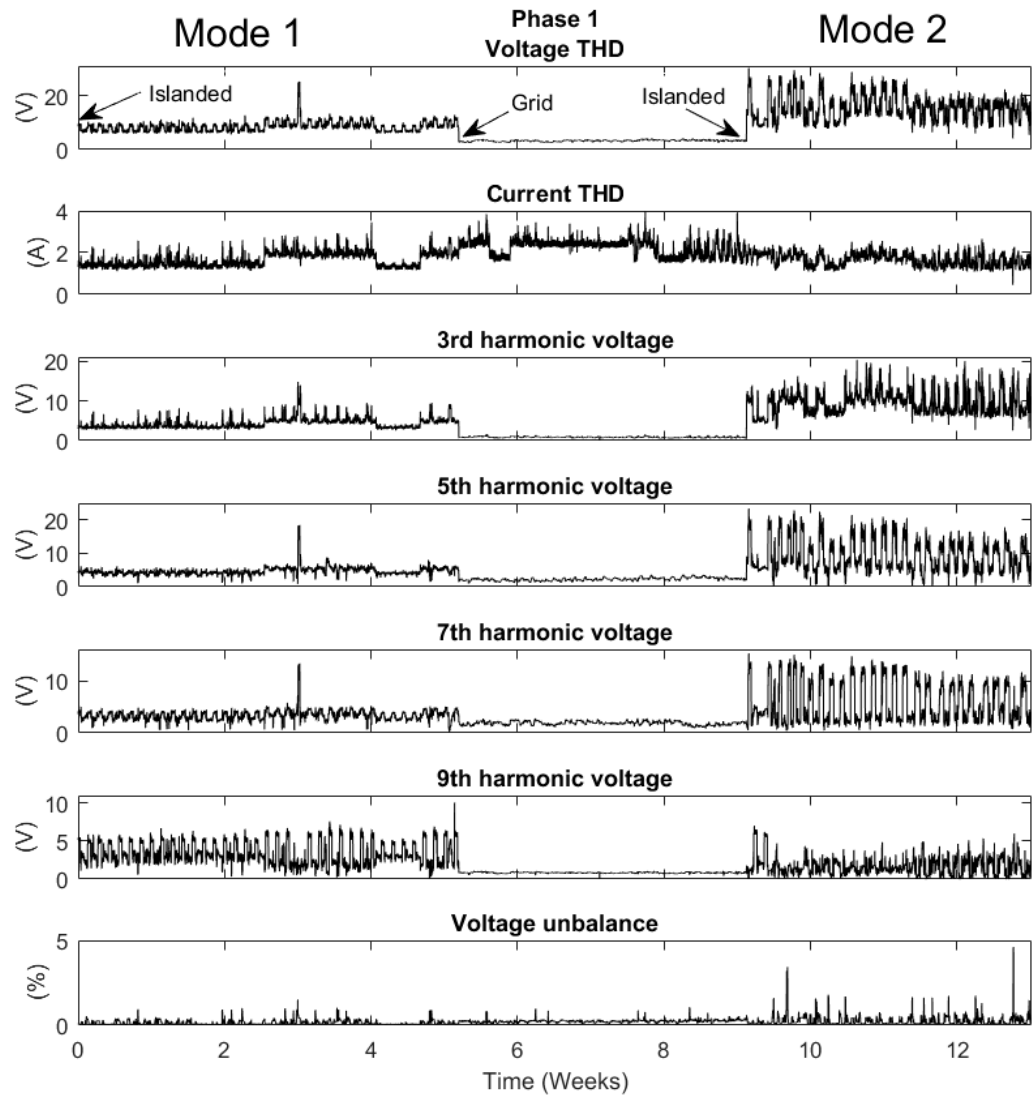

Figure 14. The voltage and current THD, 3rd, 5th, 7th, 9th harmonic voltage and voltage unbalance for phase 1 during a 13 week period in which the samples was extracted for a current rise larger than $4 \mathrm{~A}$ within 2 cycles. 

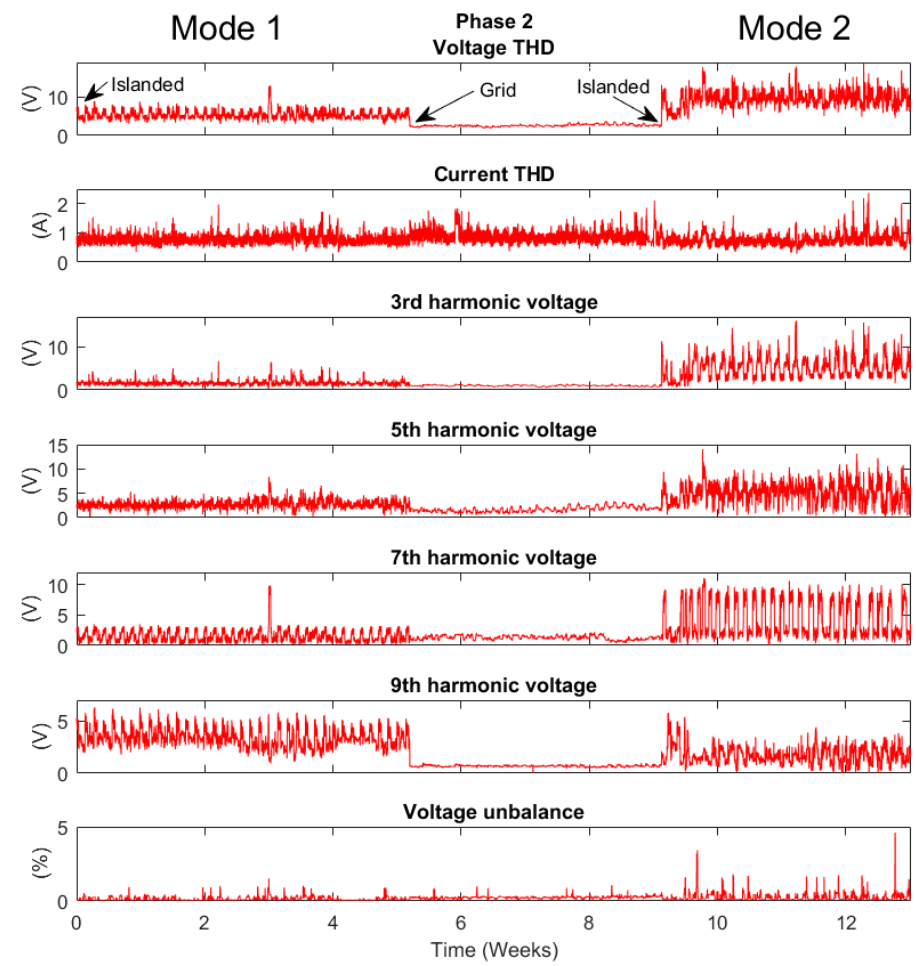

Figure 15. The voltage and current THD, 3rd, 5th, 7th, 9th harmonic voltage and voltage unbalance for phase 2 during a 13 week period in which the samples was extracted for a current rise larger than $4 \mathrm{~A}$ within 2 cycles.
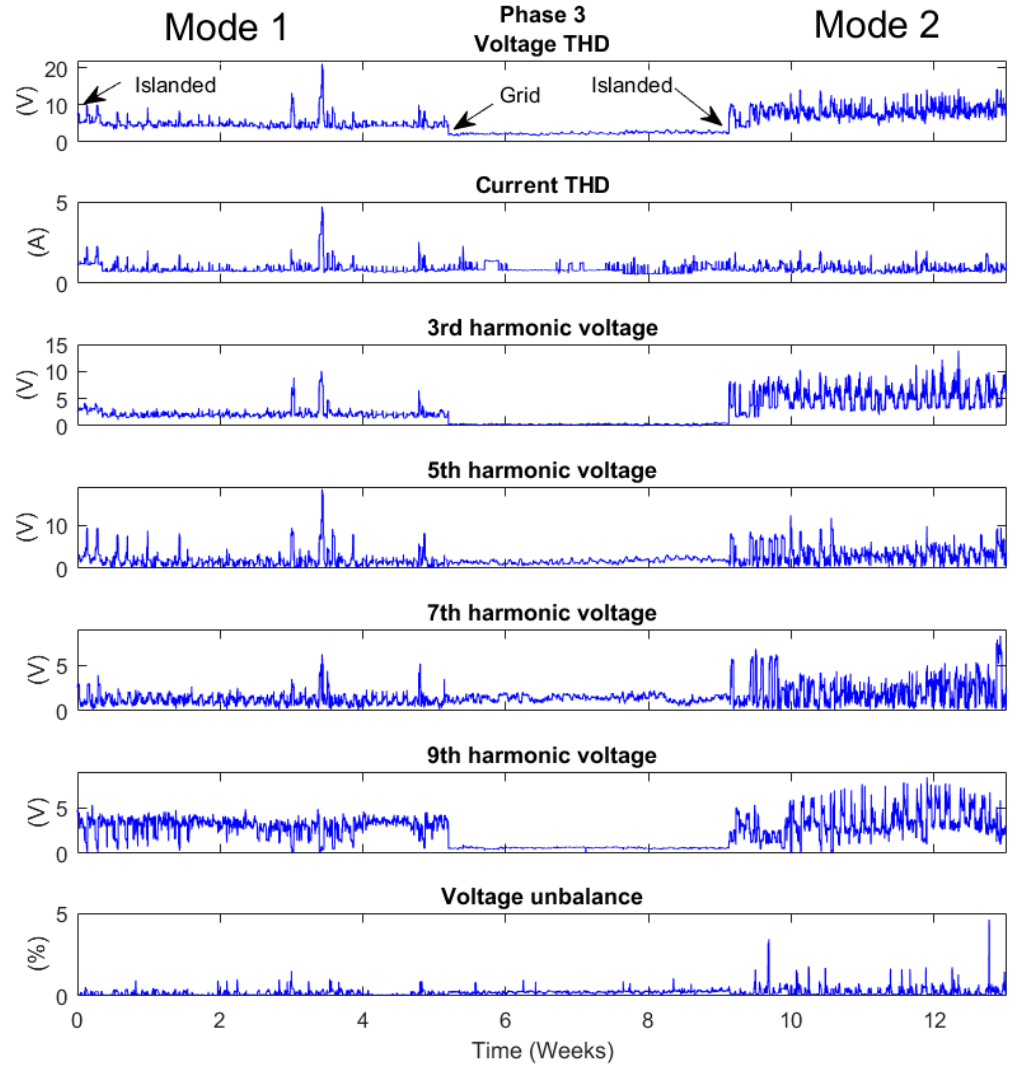

Figure 16. The voltage and current THD, 3rd, 5th, 7th, 9th harmonic voltage and voltage unbalance for phase 3 during a 13 week period in which the samples was extracted for a current rise larger than $4 \mathrm{~A}$ within 2 cycles. 
The average short circuit impedance for each hour during the day for around 8 weeks in islanded operation seen in Figure 13 can be seen in Figure 17. The blue and red line represents mode 1 and mode 2 respectively seen in Figure 13. The amount of samples for phase 1 to 3 is around 31,000, 730, 11,000 respectively, therefore phase 2 doesn't have samples for some hours during the day. It can be seen that the short circuit impedance is larger during the beginning of the day for phase 1 and larger during the middle of the day for phase 3. For phase 2 there are not enough samples to clearly see the variation during the day. However, for all three phases it can be seen that the short circuit impedance has a higher average for each hour during the day during mode 2 in islanded operation.
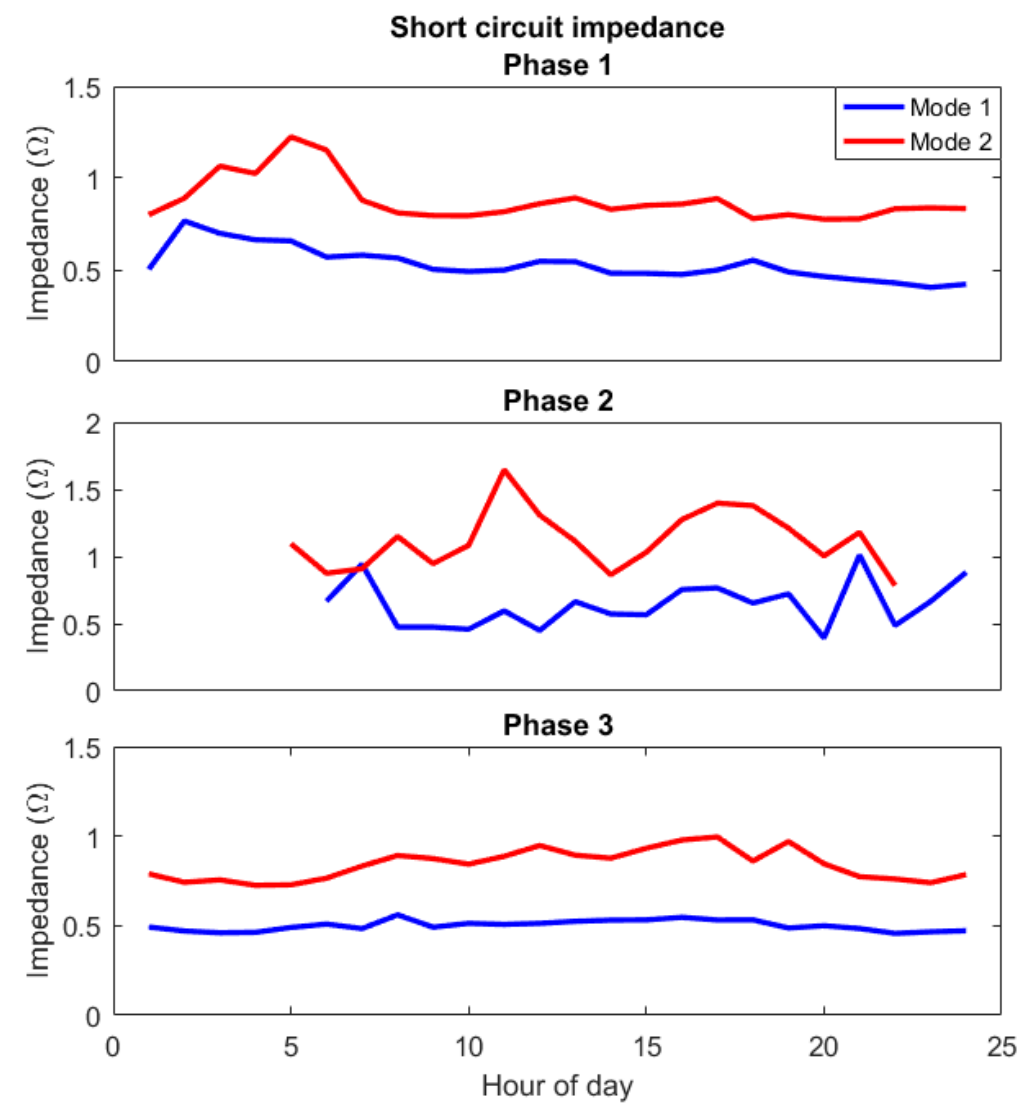

Figure 17. The average short circuit impedance for each hour of the day for around 8 weeks in islanded operation for Mode 1 and Mode 2 seen in Figure 13.

The average values for each hour of the day for around 8 weeks in islanded operation for the 3rd to 9th odd harmonic voltages, currents and voltage THD for mode 1 in Figures 14-16 can be seen in Figure 18. Mode 1 has larger 7th and 9th harmonic voltages and currents during the night for all three phases and the 5th harmonic has larger values for phase 1 and 3. The 3rd harmonic is more evenly distributed across the day where the 3rd harmonic has larger average voltage and current values during the middle of the day. The voltage THD has the largest values during the night which corresponds with the result from the longer 29 week measurements presented in Figure 3. 

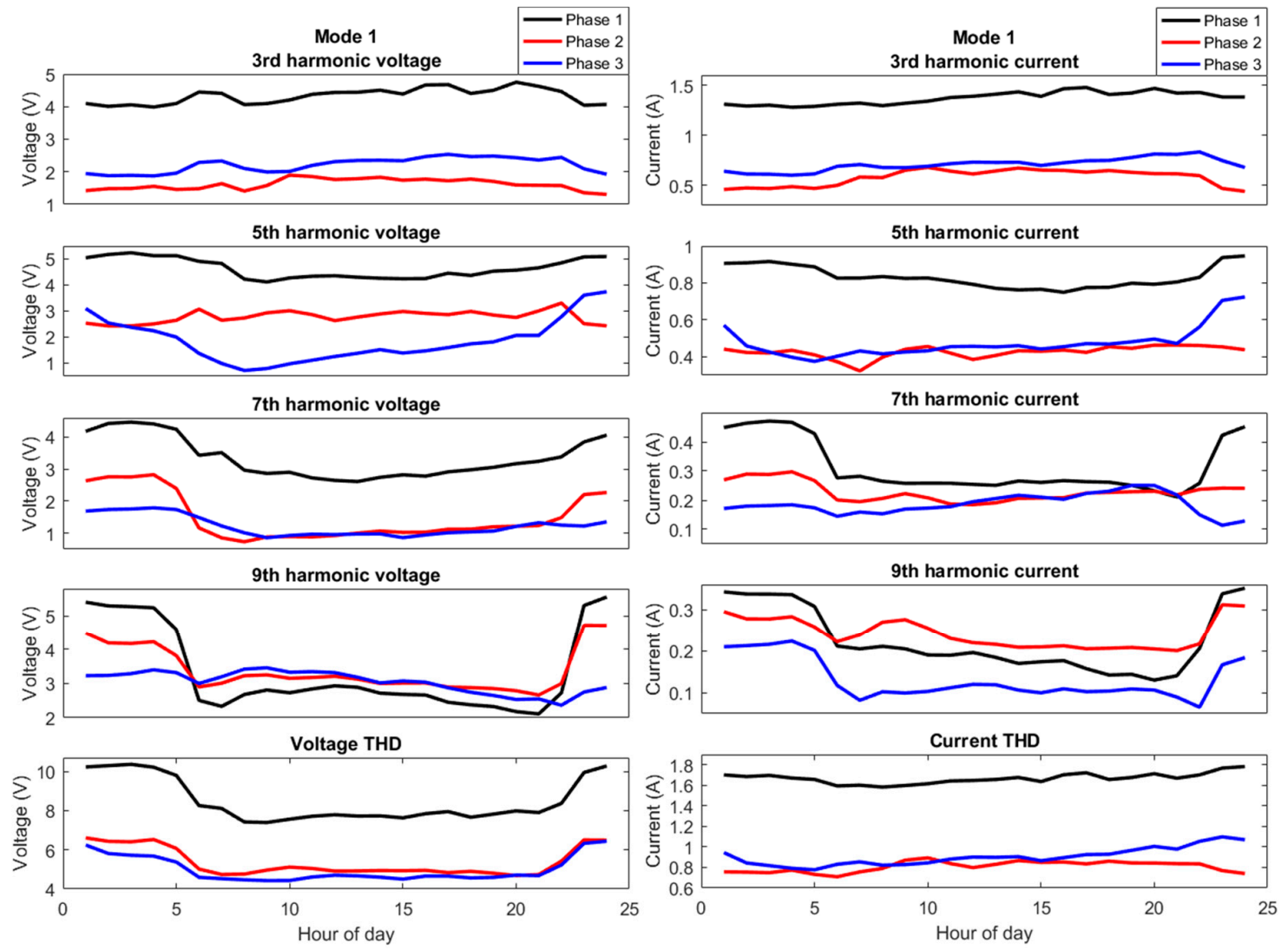

(a)

(b)

Figure 18. (a) The odd harmonic voltage 3rd to 9th and THD for mode 1 in Figures 14-16. (b) The odd harmonic current 3 rd to 9 th and THD for mode 1 in Figures 14-16. The average values are grouped for each hour of the day for around 8 weeks of islanded operation. Note also the difference in vertical scale for the different plots.

The average values for each hour during the day for around 8 weeks in islanded operation for the 3rd to 9th odd harmonic voltages, currents and THD for mode 2 in Figures 14-16 can be seen in Figure 19. The average 3rd harmonic voltage is larger during the middle of the day and with larger magnitude than in Figure 18. The 5th and 7th harmonic has the largest voltage distortion levels during the night for all 3 phases and larger variation between night and day in comparison to mode 1 seen in Figure 18. The 9th harmonic voltage is larger during the night for phase 3 and higher during the middle of the day for phase 1 and 2. The voltage THD has the largest values during the night which corresponds with the result from the longer 29 week measurements presented in Figure 3. The harmonic current levels follow the same pattern for some of the voltage harmonics but have opposite pattern for other voltage harmonics. This indicates that there are more factors that act on the voltage distortion than the current distortion.

In Figure 20, the $1 \mathrm{~h}$ average values are plotted for the 3rd and 5th harmonic current and voltage for around 8 weeks in islanded operation. The blue colored values are for mode 1 and the red colored values are for mode 2 seen in Figures 14-16. The inclination (slope) corresponds to the impedance which is higher for mode 2 than for mode 1 . However, for mode 1 the values form a more linear behavior than for mode 2. For the 3rd harmonic in phase 3, there is an appearance of a large area that has variation in voltage distortion without an increase in current distortion magnitude. 

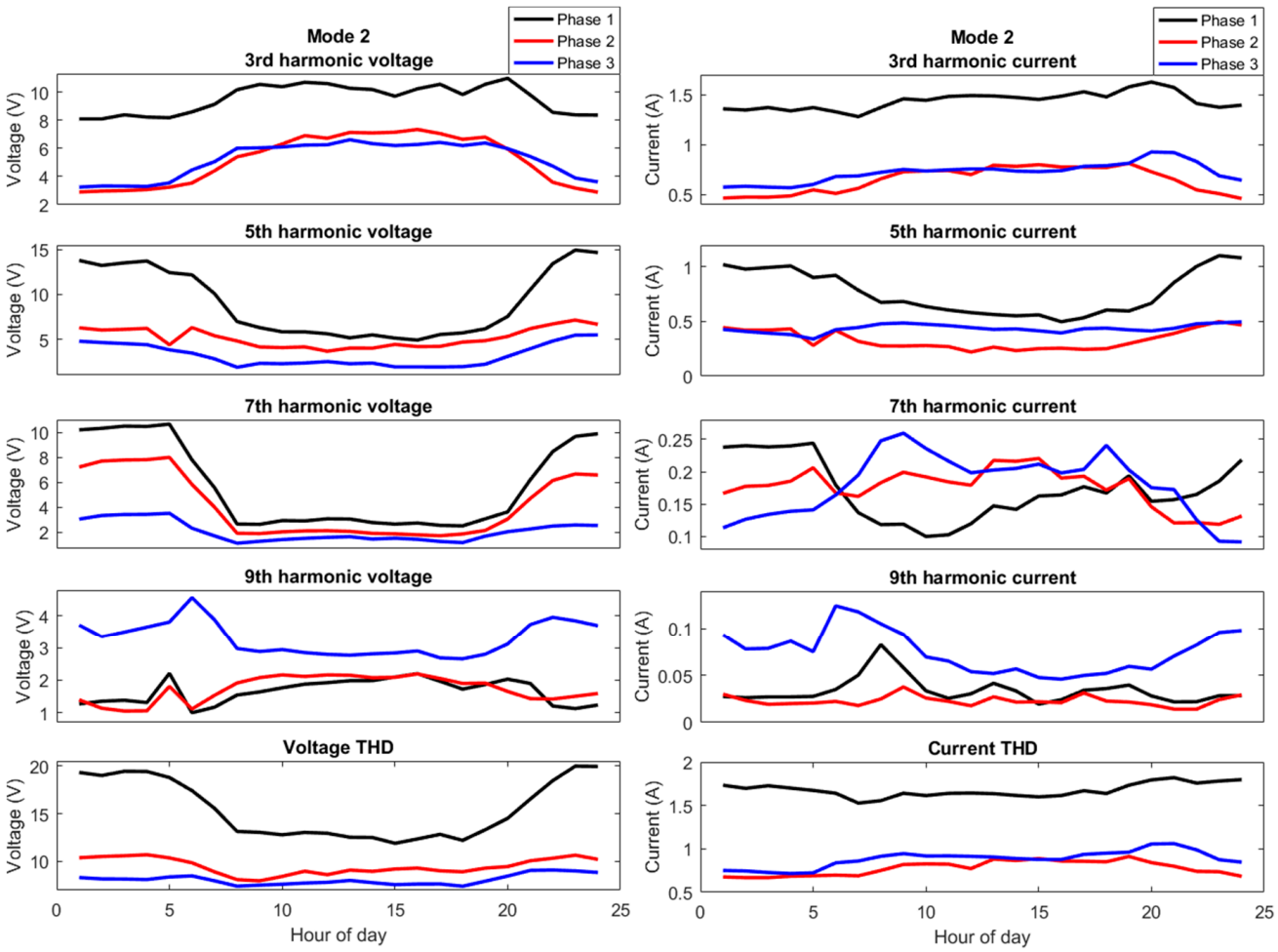

(a)

(b)

Figure 19. (a) The odd harmonic voltage 3rd to 9 th and THD for mode 2 in Figures $14-16$. (b) The odd harmonic current 3rd to 9 th and THD for mode 2 in Figures 14-16. The average values are grouped for each hour of the day for around 8 weeks of islanded operation. Note also the difference in vertical scale for the different plots.
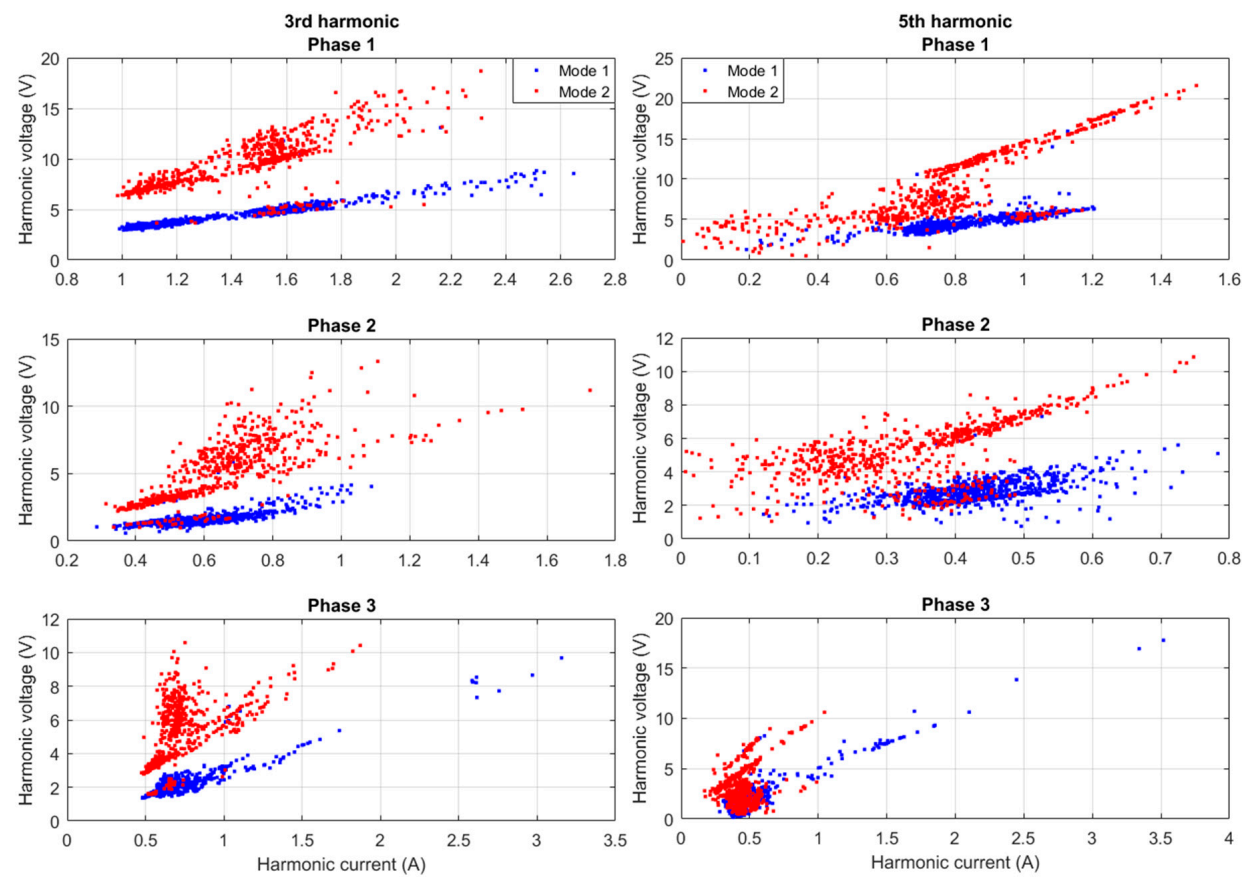

(a)

(b)

Figure 20. (a) The $1 \mathrm{~h}$ 3rd harmonic voltage and current values plotted against each other for Mode 1 and 2 seen in Figures 14-16. (b) The $1 \mathrm{~h}$ 5th harmonic voltage and current values plotted against each other for Mode 1 and 2 seen in Figures 14-16. 
Another observation is that some of the measurements for mode 1 and 2 overlap each other which are expected since no criteria for the separation of the two modes exist except for the different time windows in Figures 13-16.

In Figure 21, the $1 \mathrm{~h}$ values are plotted for the 7th and 9th harmonic current and voltage for all three phases for around 8 weeks in islanded operation. The blue colored values are mode 1 and the red colored values are for mode 2 seen in Figures 14-16. The 7th and the 9th harmonic have some linear appearance for mode 1 but not as much as the 3rd and 5th harmonic. For mode 2 the behavior is more nonlinear, where some of the voltage distortion values are located close to zero current distortion for some phases. This indicates that the voltage distortion originates from the voltage source which is one of the possible sources of error in the impedance measurements. This is more evident in the 9 th harmonic than in the 7 th harmonic.
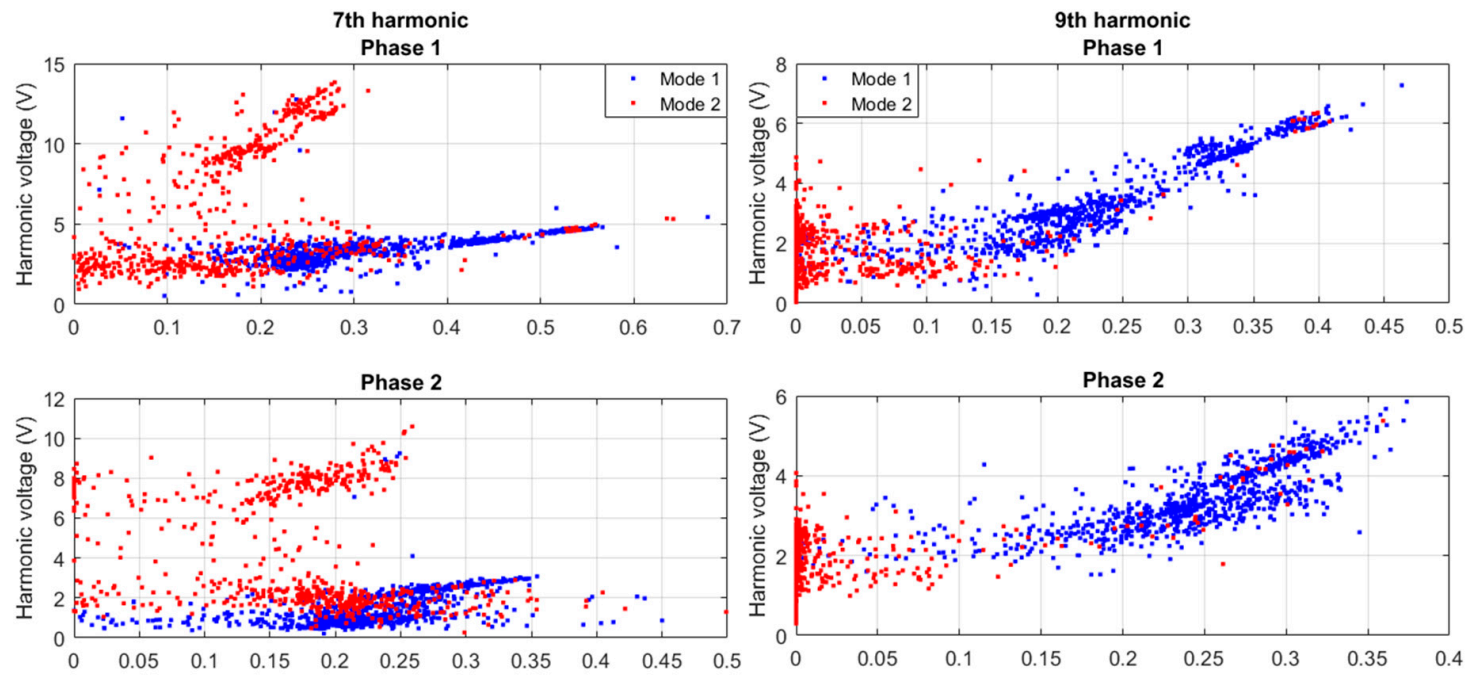

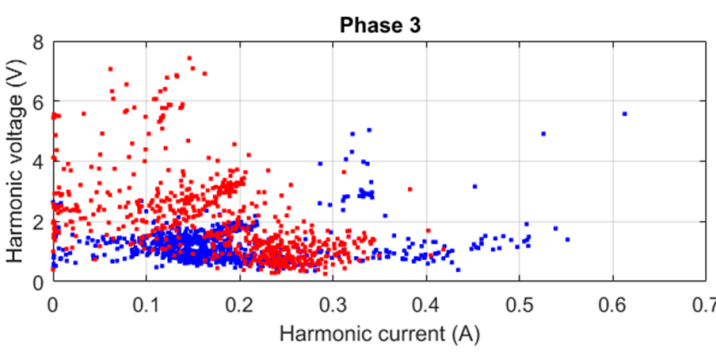

(a)

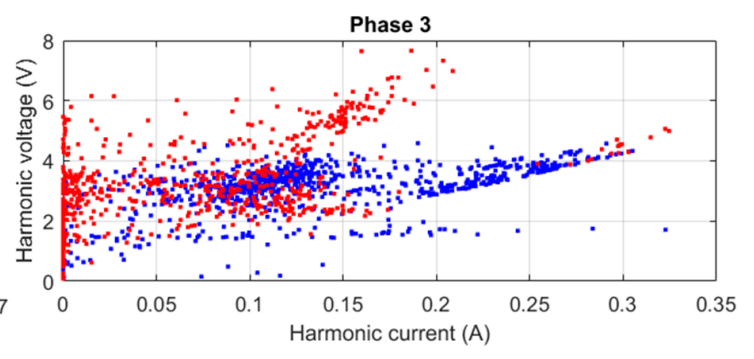

(b)

Figure 21. (a) The $1 \mathrm{~h} 7$ th harmonic voltage and current values plotted against each other for mode 1 and 2 seen in Figures 14-16. (b) The $1 \mathrm{~h}$ 9th harmonic voltage and current values plotted against each other for mode 1 and 2 seen in Figures 14-16.

\section{Comparison to Reference Values}

In this section, some of the measured values presented in Section 3 are compared to the European standard EN 50160 and the IEEE standard 519-2014.

\subsection{Voltage THD}

The allowed 10 min voltage THD for a low voltage networks is $8 \%$ for $95 \%$ of the time per week for both IEEE standard 519-2014 and European standard EN 50160. IEEE standard 519-2014 has also a $12 \%$ THD limit for $3 \mathrm{~s}$ values for $99 \%$ of the time for one day at the low voltage Point of Common Coupling (PCC).

During islanded operation the number of weeks that exceeded the $5 \%$ allowed time frame in which the 10 min voltage THD could be above $8 \%$ is shown in the upper part of Figure 22 . The total 
number of days that the $3 \mathrm{~s}$ voltage THD was over $12 \%$ for more than $1 \%$ of one day can also be seen in the upper part of Figure 22. The amount of time in which the voltage THD was over $8 \%$ and $12 \%$ can be seen in the lower part in Figure 22. Only phase 1 surpassed the 5\% weekly limit for $8 \%$ voltage THD in EN 50160 and the 1\% daily limit for 12\% voltage THD described in IEEE 519-2014. During grid-connected operation no limits was surpassed.
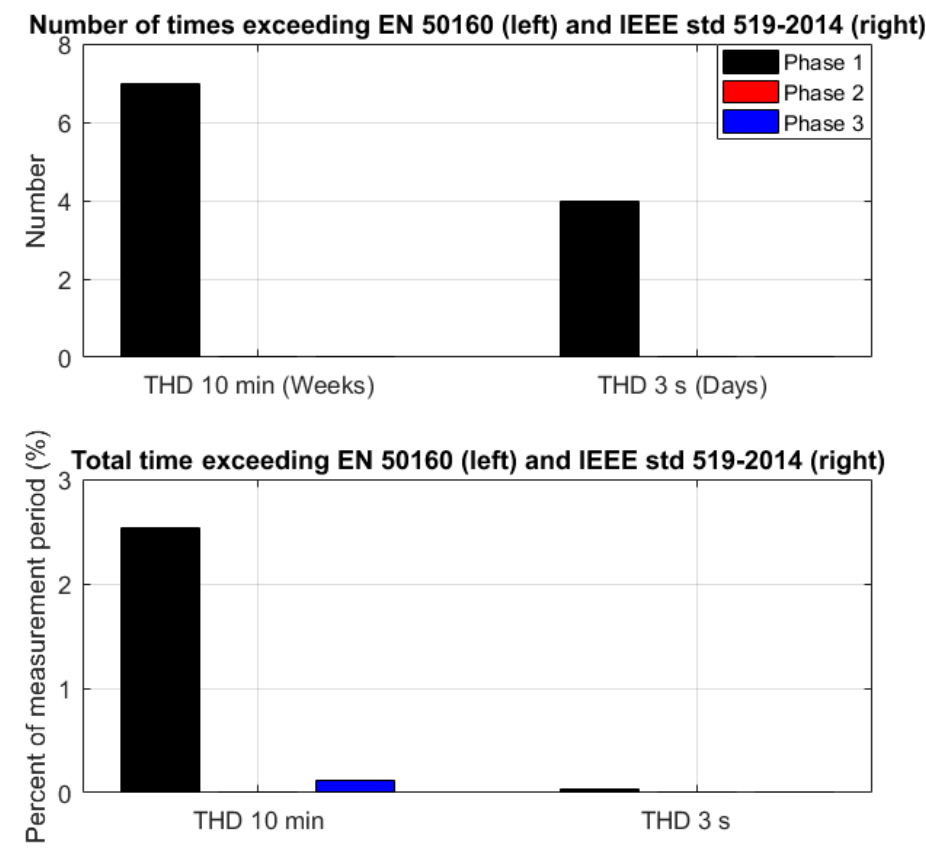

Figure 22. The number of times the voltage THD exceeded the limits in EN 50160 and IEEE 519-2014 for the $10 \mathrm{~min}$ (in weeks) and $3 \mathrm{~s}$ (in days) (top) and the amount of time in which the voltage THD exceeded the 8\% and 12\% limits in EN 50160 and IEEE 519-2014 (bottom) for all three phases during islanded operation. The measurement period was 48 weeks.

\subsection{Individual Harmonics}

For $95 \%$ of the time during one week the 10 min value of the individual harmonics shall not go beyond the limits in Table 9 from EN 50160. For IEEE 519-2014 the limit for individual harmonics is 5\% for $10 \mathrm{~min}$ values and $7.5 \%$ for $3 \mathrm{~s}$ values at a low voltage PCC.

Table 9. EN 50160 limits for individual harmonics at the low voltage Point of Common Coupling (PCC).

\begin{tabular}{cc}
\hline Harmonic Order & Percent of Fund (\%) \\
\hline 3rd & 5 \\
4 th & 1 \\
5th & 6 \\
6th & 0.5 \\
7th & 5 \\
8th & 0.5 \\
9th & 1.5 \\
11th & 3.5 \\
15th & 0.5 \\
\hline
\end{tabular}

For both islanded and grid-connected operation, the number of weeks and total time in which the individual harmonics exceeded the limits in EN 50160 is shown in Figure 23. For islanded operation some individual harmonics stays within the $5 \%$ allowed time per week but exceed the limit sometime during the measurement period. Phase 2 during islanded operation never exceeds the $5 \%$ time limit. The 15th harmonic is only surpassed for one week for phase 3 during islanded operation. It can also be 
seen that the 9th harmonic exceeds almost every week for all three phases during islanded operation. For the grid-connected measurements, the 9 th harmonic exceeded the $1.5 \%$ limit for 1 week.
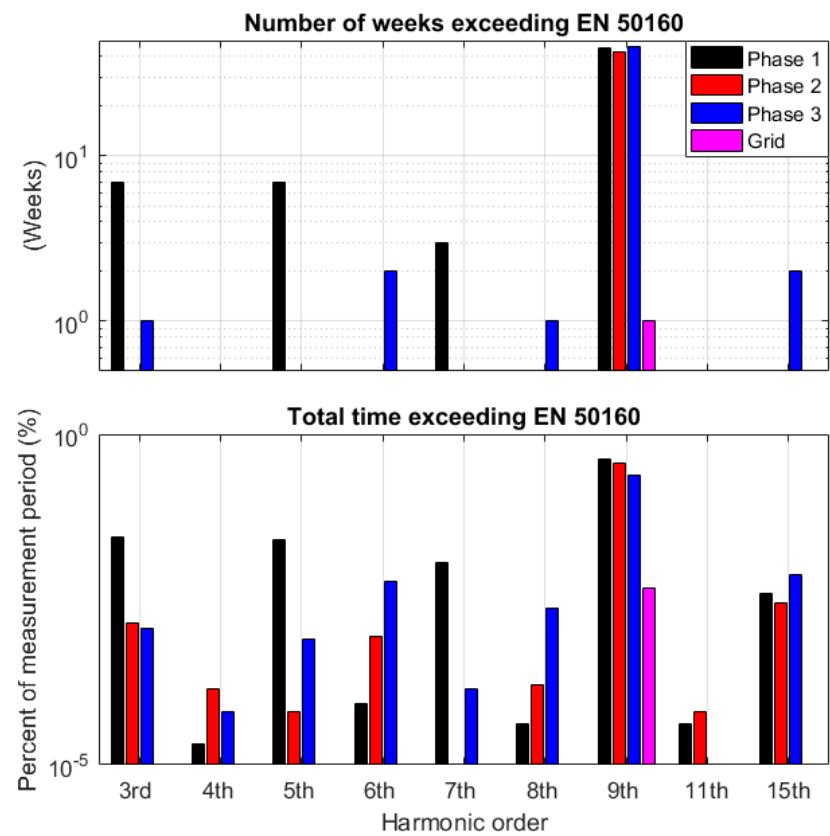

Figure 23. The number of times the individual harmonics exceeded the 10 min limits in EN 50160 (top) and the amount of time during the measurement period (48 weeks in islanded operation and 54 weeks in grid-connected operation) in which the individual harmonics exceeded the limits in EN 50160 (bottom) for islanded and grid-connected operation. Note the logarithmic vertical scale.

The number of weeks and amount of time in which the individual harmonics exceeded the limits in IEEE 519-2014 are shown in Figure 24.
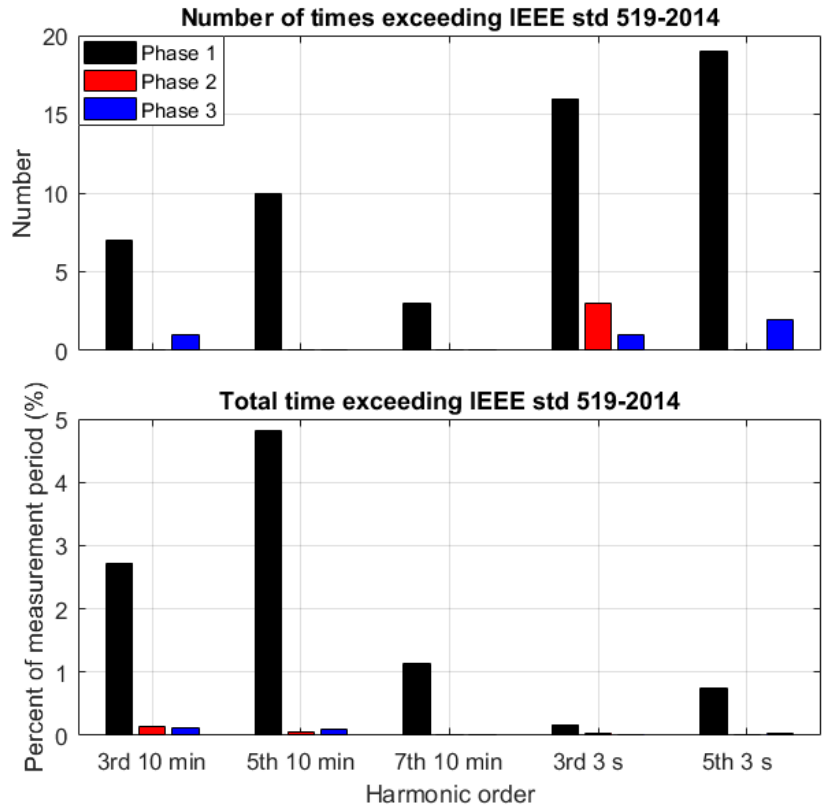

Figure 24. The number of times the individual harmonics exceeded the $10 \mathrm{~min}$ (in weeks) and $3 \mathrm{~s} \mathrm{limit}$ (in days) in IEEE 519-2014 (top) and the amount of time during the measurement period of 48 weeks in which the individual harmonics exceeded the limits in IEEE 519-2014 (bottom) for islanded operation. 
It can be seen that the 3rd, 5th and 7th harmonic are the only harmonics in the 10 min values that exceed the 5\% limit in IEEE 519-2014 during islanded operation. For the $3 \mathrm{~s}$ values the 3rd and 5 th harmonics are the ones exceeding the $7.5 \%$ limit during islanded operation. The limits were not surpassed during grid-connected operation.

\subsection{Long Term Flicker Severity}

In EN 50160 only the Plt value is specified which should be lower than 1 for $95 \%$ of the time for one week. For phase 1 and 3 the Plt value exceeded the limit for 3 weeks and phase 2 exceeded the limit for 4 weeks. The grid-connected measurements never exceeded the 5\% allowed time limit in EN 50160 . In Figure 25 the amount of time during the measurement period in which the Plt value exceeds the specified limit in EN 50160 for islanded and grid-connected is illustrated. The Plt values for islanded operation exceeded the limit in EN 50160 for about twice as long than in grid-connected operation.
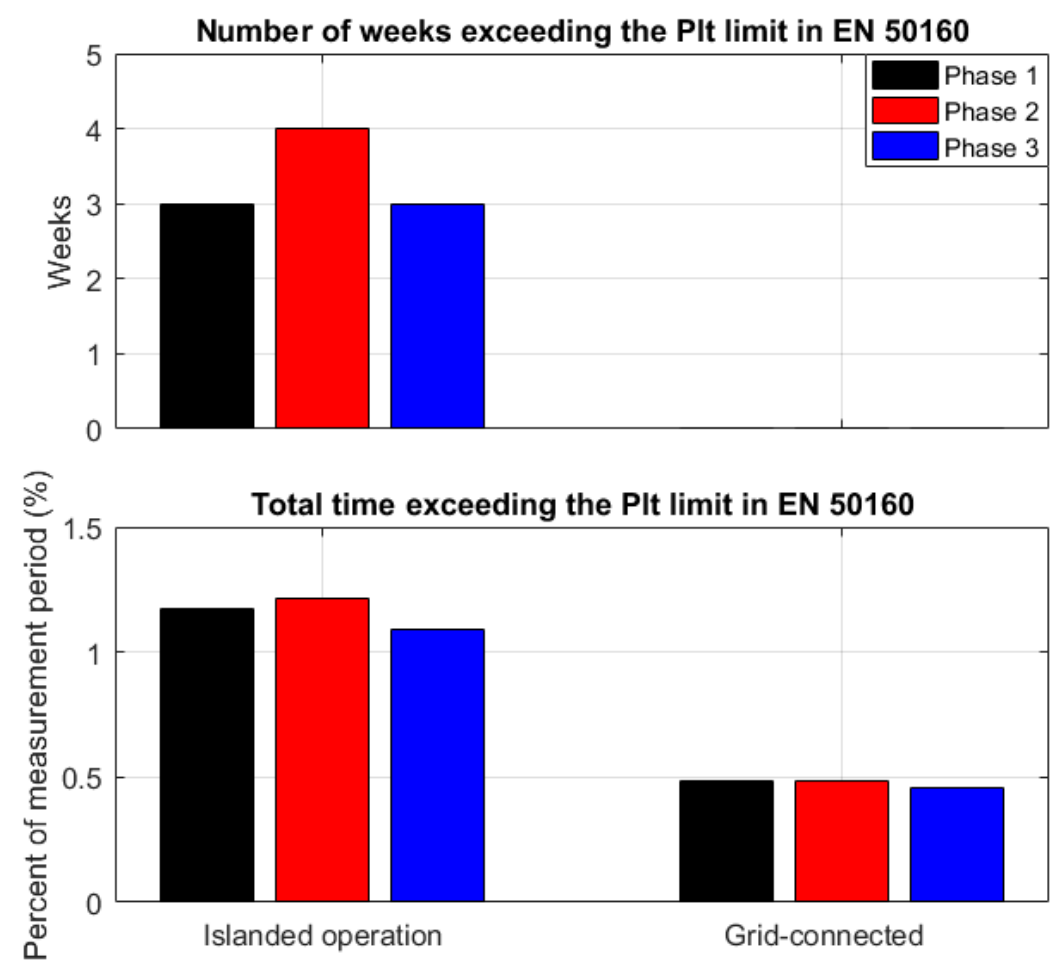

Figure 25. The number of times the Plt values exceeded the limits in EN 50160 (top) and the amount of time during the measurement period of 48 weeks in which the Plt values exceeded the limits in EN 50160 (bottom) for islanded operation.

\subsection{Voltage Unbalance}

According to EN 50160 the voltage unbalance should not go beyond $2 \%$ for more than $5 \%$ of the time for one week. In the grid-connected operation the voltage unbalance never went above $2 \%$. In islanded operation the voltage unbalance went above $2 \%$ for $2.34 \mathrm{~h}$, above $3 \%$ for $1.5 \mathrm{~h}$ in the 48 week measurements. The largest voltage unbalance during the longest consecutive time was $4.5 \%$ during $30 \mathrm{~min}$. However, the voltage unbalance was kept below $2 \%$ for more than $95 \%$ of each week.

\section{Discussion}

\section{Effects on Equipment}

It is stated in [12] that for a voltage THD between 8 and 10\% motors could get overheated. The measurements presented in Section 3 show that there can be levels that go beyond 8 and 10\% 
distortion in the nanogrid. This can lead to overheating for motors and other equipment sensitive to voltage harmonics.

Flat topping of the voltage waveform can affect switched-mode power supplies since they need a high peak voltage to effectively charge its capacitor. Since the $10 \mathrm{~min}$ voltage THD values can reach up to $13 \%$ with up to $9.3 \%$ of 3 rd harmonic content, equipment that has switched-mode power supplies could also suffer from excess heating. Especially harmonics 5 and 7 can also cause more losses in electrical motors and a counter electromotive force that leads to torque and vibration problems. Fluctuations in the voltage can affect several types of equipment (excluding flicker). One of those effects is accelerating or braking torques in motors, deterioration of electronic equipment in which the voltage fluctuations pass through the power supply to the electronic equipment such as computers, printers, control units, components for telecommunication $[13,14]$. In a production facility, these fluctuations could lead to variations in the speed of motors that cause unacceptable variations in production parameters such as color and diameter. There is no standard today that defines acceptable levels of VSV. Since the majority VSV values are lower in islanded operation than for grid-connected operation, there is an improvement of the performance in islanded operation when comparing to grid-connected operation. However, more research is needed before any conclusion can be drawn on how equipment will perform under high VSV values.

The main effect of high Pst and Plt values is light flicker for incandescent lamps. Since the nanogrid only has LED lamps there could be either less or more light flicker depending on which LED lamp is used [15]. The difference in voltage flicker levels was larger between one phase and the other two phases for the majority of the time in islanded operation. This might suggest that the connected equipment might affect the flicker levels in a certain phase more in islanded operation than in grid operation since the flicker levels in the three phases during grid operation were closer to each other.

The winding temperature increase in percent above rated temperature as a function of the voltage unbalance can be calculated from Equation (1) [16]:

$$
\text { Temp rise }=2(\text { Percent unbalance })^{2}
$$

From Equation (1) a temperature rise of $40.5 \%$ for $30 \mathrm{~min}$ could occur during the 48 week measurements for islanded operation. The maximum temperature rise would be $42.3 \%$ for $10 \mathrm{~min}$. The average winding temperature increase for islanded operation is about $0.1 \%$ and about $0.2 \%$ for grid-connected operation. The reduction in lifetime of the motor due to temperature increase following the Arrhenius model is described in IEEE standard 101 [17]. Since the average winding temperature for a 3-phase motor is lower in islanded operation than in grid-connected operation, the lifetime of a 3-phase motor might increase in islanded operation. However, since there are times in which the motor can run on temperature elevations of up to $42.3 \%$ for shorter time periods at the same time as the voltage THD is above $8 \%$ (Mode 2 in Figure 14), a decrease in the lifetime of a motor could happen in comparison to grid-connected operation.

\section{Conclusions}

The voltage THD and individual harmonics reach larger values in islanded operation than in grid-connected operation. The difference in magnitude between the phases is also larger in islanded operation.

- Figure 5 shows that the voltage THD increases during the evening without a change in load which suggests that the system impedance increases due to fewer parallel sources being active. This could be due to the shutdown of the solar inverter in the evening. The subsequent decrease in voltage harmonics levels in the morning could be caused by the activation of the solar inverter.

- During islanded operation the Pst and Plt values were lower for the majority of the time for phase 2 while the other two are for the majority of the time higher in islanded operation. 
- The $10 \mathrm{~min}$ and $3 \mathrm{~s} \mathrm{VSV}$ value are for the majority of the time lower in islanded operation for all three phases. It can therefore be concluded that voltage variations on timescales $3 \mathrm{~s}$ to $10 \mathrm{~min}$ are lower in islanded operation.

- The voltage unbalance is lower for the majority of the time in islanded operation but could reach levels of over $4.5 \%$ for 30 consecutive minutes in islanded operation.

- Figures 13-21 show that there are two modes of performance during islanded operation. Mode 2 operates with larger values of the short circuit impedance, voltage THD, voltage unbalance and individual voltage harmonics 3, 5, 7 for all three phases. For phase 3, the 9th harmonic voltage was also larger during mode 2 . Mode 1 operates with a larger 9th harmonic voltage for phase 1 and 2 . The 3rd harmonic impedance behaves almost linear in both modes and is larger during mode 2 for all three phases. The 5 th harmonic impedance behaves more nonlinear but is generally larger during mode 2 for two phases. The 7th and 9th harmonic impedance show nonlinear behavior and no conclusion can be made regarding the magnitude of the harmonic impedance for the 7th and 9th harmonic.

- When the islanded operation was compared to the limits defined in grid standard EN 50160 it was found that the voltage THD, individual harmonics $3,5,6,7,9,15$, voltage unbalance and Plt limits were exceeded. For one week the 9th harmonic exceeded the limit during grid-connected operation.

- When the islanded operation was compared to the limits defined in grid standard IEEE 519-2014 it was found that the voltage THD, individual harmonics 3, 5, 7 were exceeded. The limits were not exceeded during grid-connected operation.

More studies with long term measurements are needed to see if similar results are obtained for other nanogrids.

Author Contributions: Conceptualization, J.N., S.K.R. and M.H.J.B.; Methodology, J.N.; Software, J.N.; Validation, J.N., S.K.R. and M.H.J.B.; Formal Analysis, J.N.; Investigation, J.N.; Resources, S.K.R. and M.H.J.B.; Data Curation, J.N.; Writing-Original Draft Preparation, J.N.; Writing-Review \& Editing, J.N., S.K.R. and M.H.J.B.; Visualization, J.N.; Supervision, S.K.R. and M.H.J.B.; Project Administration, S.K.R. and M.H.J.B.; Funding Acquisition, S.K.R. and M.H.J.B.

Funding: This paper has been funded by Skellefteå Kraft Elnät and Rönnbäret foundation.

Conflicts of Interest: The authors declare no conflict of interest.

\section{References}

1. Hatziargyriou, N. Microgrids Architectures and Control, 1st ed.; Wiley-IEEE Press: Hoboken, NJ, USA, 2014; pp. 310-313.

2. Hatziargyriou, N.; Asano, H.; Iravani, R.; Marnay, C. Microgrids. IEEE Power Energy Mag. 2007, 5, 78-94. [CrossRef]

3. CIGRÉ WG C6.22. Microgrids 1: Engineering, Economics, E Experience; The International Council on Large Electric Systems: Paris, France, 2015.

4. Burmester, D.; Rayudu, R.; Seah, W.; Akinyele, D. A review of nanogrid topologies and technologies. Renew. Sustain. Energy Rev. 2017, 67, 760-775. [CrossRef]

5. Cenelec Std. EN 50160:2010. Voltage Characteristics of Electricity Supplied by Public Electricity Networks; European Committee for Electrotechnical Standardization: Brussels, Belgium, 2010.

6. IEEE Std. 519-2014. IEEE Recommended Practice and Requirements for Harmonic Control in Electric Power Systems; IEEE Standards Association: Piscataway, NJ, USA, 2014.

7. Nömm, J.; Rönnberg, S.K.; Bollen, M.H.J. An Analysis of Frequency Variations and its Implications on Connected Equipment for a Nanogrid during Islanded Operation. Energies 2018, 11, 2456. [CrossRef]

8. Rönnberg, S.K.; Bollen, M.H.J.; Nömm, J. Power Quality Measurements In a Single House Microgrid. In Proceedings of the CIRED 24th International Conference on Electricity Distribution, Glasgow, Scotland, UK, 12-15 June 2017; pp. 818-822. 
9. Nömm, J.; Rönnberg, S.K.; Bollen, M.H.J. Harmonic Voltage measurements in a Single House Microgrid. In Proceedings of the ICHQP 18th International Conference on Harmonics and Quality of Power, Ljubljana, Slovenia, 13-16 May 2018; pp. 1-5.

10. Bollen, M.H.J.; Häger, M.; Schwaegerl, C. Quantifying voltage variations on a time scale between 3 seconds and 10 minutes. In Proceedings of the CIRED 18th International Conference and Exhibition on Electricity Distribution, Turin, Italy, 6-9 June 2005; pp. 1-5.

11. Bollen, M.H.J.; Gu, I.Y.H. Characterization of voltage variations in the very-short time-scale. IEEE Trans. Power Deliv. 2005, 20, 1198-1199. [CrossRef]

12. Dugan, R.C.; McGranaghan, M.F.; Santoso, S.; Beaty, H.W. Electrical Power System Quality, 2nd ed.; McGraw-Hill Education: New York, NY, USA, 2003; p. 216.

13. Schlabbach, J.; Blume, D.; Stephanblome, T. Voltage Quality in Electrical Power Systems; The Institution of Electrical Engineers: Stevenage, UK, 2001; pp. 115-116.

14. UIE WG 2. Guide to Quality of Electrical Supply for Industrial Installations, Part 5; Flicker and Voltage Fluctuations; International Union for Electricity Applications: Paris, France, 1999; p. 13.

15. Gil-de-Castro, A.; Rönnberg, S.K.; Bollen, M.H.J. Light intensity variation (flicker) and harmonic emission related to LED lamps. Electr. Power Syst. Res. 2017, 146, 107-114. [CrossRef]

16. Pillay, P.; Manyage, M. Derating of Induction Motors Operating With a Combination of Unbalanced Voltages and Over or Undervoltages. IEEE Trans. Energy Convers. 2002, 17, 485-491. [CrossRef]

17. IEEE Std. 101-1987(R2010). Guide for the Statistical Analysis of Thermal Life Test Data; IEEE Standards Association: Piscataway, NJ, USA, 2010.

(C) 2019 by the authors. Licensee MDPI, Basel, Switzerland. This article is an open access article distributed under the terms and conditions of the Creative Commons Attribution (CC BY) license (http:/ / creativecommons.org/licenses/by/4.0/). 